\title{
Geophysical investigation of the T and T Mine Complex, Preston County, West Virginia
}

Jennifer S. Mabie

West Virginia University

Follow this and additional works at: https://researchrepository.wvu.edu/etd

\section{Recommended Citation}

Mabie, Jennifer S., "Geophysical investigation of the T and T Mine Complex, Preston County, West Virginia" (2003). Graduate Theses, Dissertations, and Problem Reports. 1763.

https://researchrepository.wvu.edu/etd/1763

This Thesis is protected by copyright and/or related rights. It has been brought to you by the The Research Repository @ WVU with permission from the rights-holder(s). You are free to use this Thesis in any way that is permitted by the copyright and related rights legislation that applies to your use. For other uses you must obtain permission from the rights-holder(s) directly, unless additional rights are indicated by a Creative Commons license in the record and/ or on the work itself. This Thesis has been accepted for inclusion in WVU Graduate Theses, Dissertations, and Problem Reports collection by an authorized administrator of The Research Repository @ WVU. For more information, please contact researchrepository@mail.wvu.edu. 


\title{
Geophysical Investigation of the T and T Mine Complex, Preston County, West Virginia
}

\author{
Jennifer S. Mabie \\ Thesis submitted to the College of Arts and \\ Sciences at West Virginia University \\ in partial fulfillment of the requirements \\ for the degree of \\ Master of Science \\ in \\ Geology
}

Committee Members:

Dr. Thomas H. Wilson, chair

Dr. Timothy Warner

Mr. Richard Hammack, USDOE

Department of Geology and Geography

Morgantown, WV

2003

Keywords: Geophysics, Airborne Geophysics, Remote Sensing, Terrain Conductivity, Resistivity, Soundings, Preston County 


\section{ABSTRACT \\ Geophysical Investigations of the T and T Mine Complex, Preston County, West Virginia}

\section{Jennifer S. Mabie}

The U.S. Department of Energy National Energy and Technology Laboratory have utilized an airborne platform with remote sensing technologies consisting of a multi-spectral scanner and airborne electromagnetic conductivity technologies to provide a rapid reconnaissance of watershed areas. Airborne surveys were flown over the T\&T Mine Complex, located in Preston County, West Virginia. The electromagnetic and thermal anomalies observed in the airborne data were compared to mine maps to correlate anomalous features with mine pools and ground water discharge points that may represent acid mine drainage (AMD). Surface geophysical studies were performed to delineate the conductivity anomalies observed in the airborne data. The geophysical surveys were not able to resolve the mine pool at a depth of 90 meters; however, there was resolution between airborne and ground survey results up to a depth of 40 meters. The thermal data was not able to resolve groundwater discharge points that may represent AMD. 
Acknowledgements

I would like to thank many of the individuals and organizations that helped to make this work possible. I would like the thank Terry Ackman and Richard Hammack from the USDOE/NETL, Clean Water Team for the providing me with an opportunity to participate in the University-Partnership Program, allowing me to use the data, facilities, and equipment belonging to the DOE. Thanks, Rick, for keeping me on task. I would also like to thank Garret "The Fabric" Veloski and Jim Sams and other members of the Clean Water Team for all of your help. I would like to thank Tim Warner for his time and interest in the thermal aspects of this research project. I would like to give a special thanks to my advisor, Tom Wilson, for the continuous support, encouragement, and patience throughout the duration of this project and for giving me the University Partnership opportunity. Finally, I would like to thank my family and friends who have helped me physically, emotionally, spiritually, and financially over the years. 


\section{TABLE OF CONTENTS}

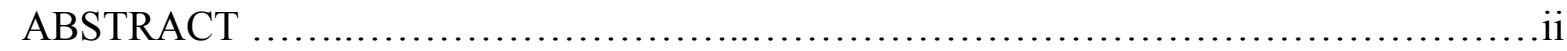

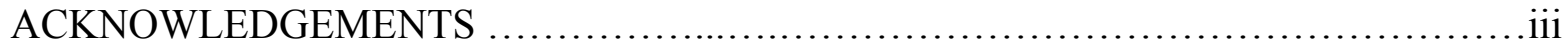

TABLE OF CONTENTS ............................................................ iv

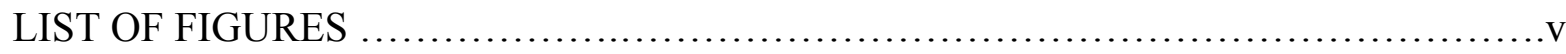

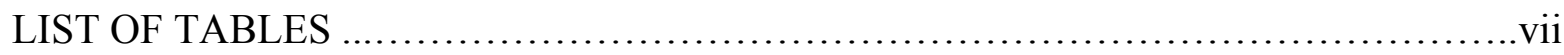

CHAPTER 1 - Introduction ..........................................................

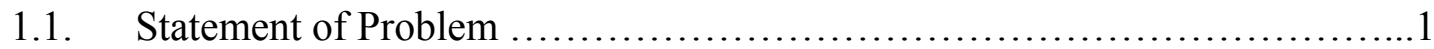

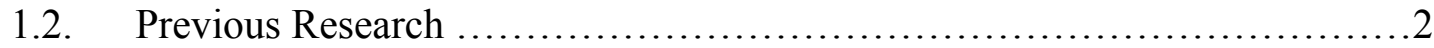

1.3. Purpose and Objectives .................................................

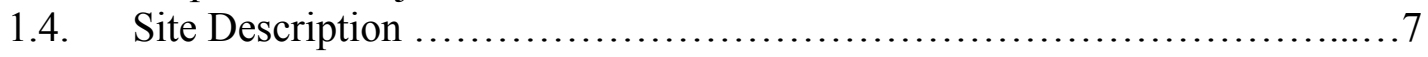

CHAPTER 2 - Review of Geophysical and Remote Sensing Methods for Environmental Applications................................................................. 11

2.1. Terrain Conductivity ................................................. 11

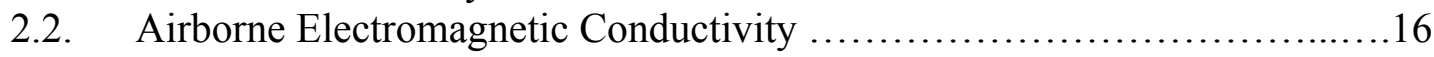

2.3. Resistivity ............................................................ 17

2.4. Time Domain Electromagnetic Method ................................ 19

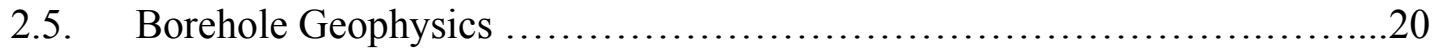

2.6. Thermal Infrared Imagery ..............................................

CHAPTER 3 - Modeling Results and Discussion - Ground............................26

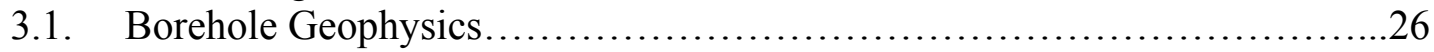

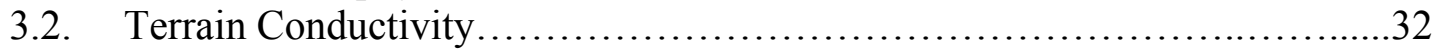

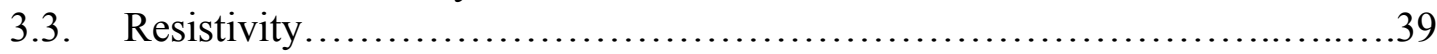

3.4. Time Domain Electromagnetic Method.....................................43

CHAPTER 4 - Modeling Results and Discussion - Airborne $\ldots \ldots \ldots \ldots \ldots \ldots \ldots \ldots \ldots \ldots . \ldots \ldots 4$

4.1. Electromagnetic Conductivity.........................................4

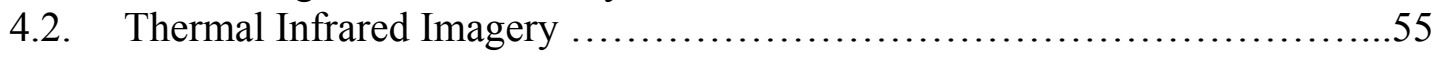

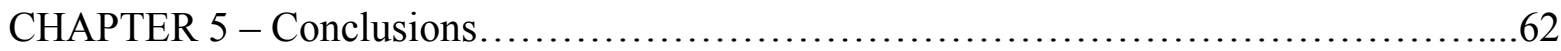

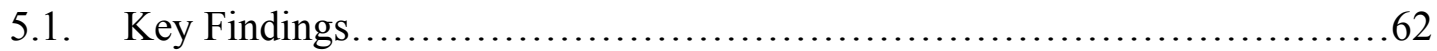

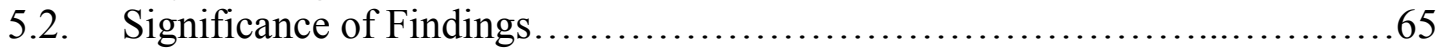

5.3. Suggestions for Future Work............................................65

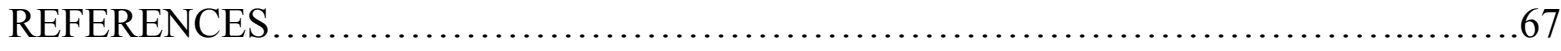




\section{LIST OF FIGURES}

Figure 1. Location map of the T\&T Mine Complex, Preston County, WV ........7

Figure 2. Stratigraphic Column of the T\&T Mine Complex......................

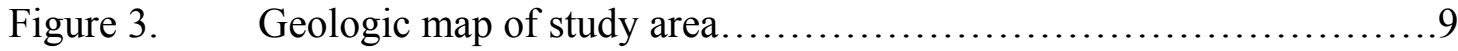

Figure 4. Well locations, locations of mine pools and surface mined areas........10

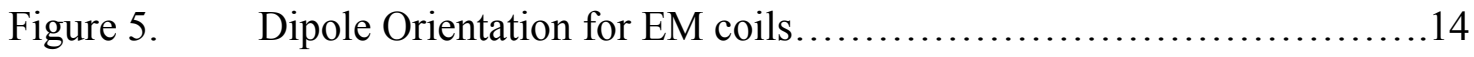

Figure 6. Comparison of relative response functions for $\mathrm{H}$ and $\mathrm{V}$ dipoles........14

Figure 7. Cumulative response function.................................. 15

Figure $8 . \quad$ Layered-earth model........................................... 16

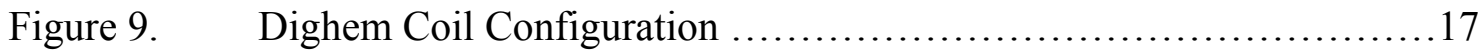

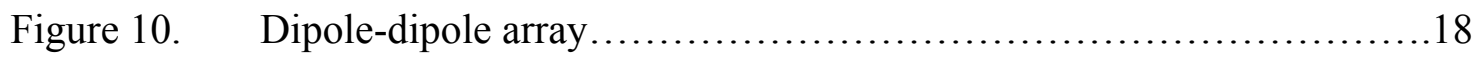

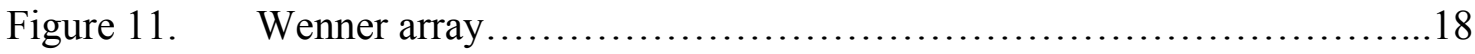

Figure 12. Square waves induced by TDEM methods..........................20

Figure 13. Atmospheric absorption of the wavelength range $0-15 \mu \mathrm{m} \ldots \ldots \ldots \ldots \ldots . \ldots 23$

Figure 14. Diurnal radiant temperature variations.............................23

Figure 15. Induction logs for Wells 1-01 to 3-01 ..........................................27-28

Figure 16. Cumulative Conductance for each well..........................29-30

Figure 17. Averaged Layers from Induction Logs.............................31-32

Figure 18. Observed and Calculated Conductivities at Each Well..................35

Figure 19. Well log and inverse model for Well 1-01, 2-01, 3-01 ....................36

Figure 20. Observed and Calculated Conductivity Data from Inverse Models.......38

Figure 21. Calculated differences in mine layer with varying conductivities........39 
Figure 22. Psuedosection of inverse model of dipole-dipole array................39

Figure 23. Psuedosection of inverse model of Wenner array....................41

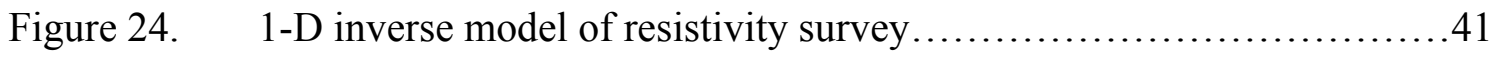

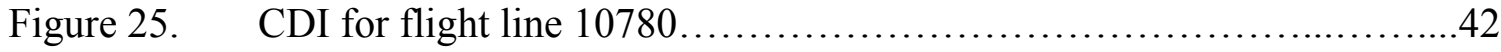

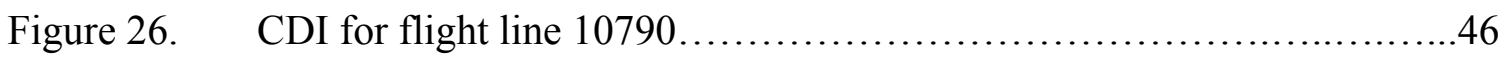

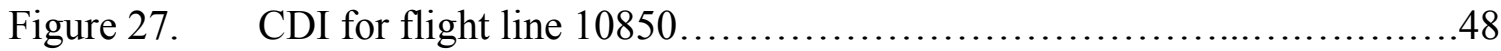

Figure 28. Airborne Conductivity Model......................................50

Figure 29. Comparison of airborne and surface data for Well $1-01 \ldots \ldots \ldots \ldots . . . . .52$

Figure 30. Comparison of airborne and surface data for Well 2-01 ...............53

Figure 31. Comparison of airborne and surface data for Well 3-01 ..............54

Figure 32. TIR overlain on a DOQQ $\quad$ T..................................... 56

Figure 33. Pseudocolor image of the TIR data...............................57

Figure 34. Thermal anomaly associated with livestock......................59

Figure $35 . \quad$ TIR of reclaimed area.............................................. 


\section{LIST OF TABLES}

Table 1. Skin depths for various airborne frequencies.....................13

Table $2 . \quad$ GIS layer information............................................. 


\section{CHAPTER 1 - Introduction}

\subsection{Statement of Problem}

The production of acid mine drainage (AMD) from coal mining sites in the Appalachian area of the United States is a major environmental issue that receives much attention in affected communities. Remedial procedures are often initiated in response to the need to be in compliance with Surface Mining Control and Reclamation Act water quality standards. However, reclamation efforts are usually based on very little subsurface information. In most cases, geophysical assessment of the area is not available. Lack of site-specific subsurface information often limits the effectiveness and increases the cost of remedial action.

Acid mine drainage is generally associated with an increase in concentration of heavy metals and other ionic species that increase specific conductance of ground and surface waters. This increase in conductance makes mapping of AMD ground water contamination using geophysical methods a low cost alternative to collecting subsurface data. Acid mine drainage has had a significant impact on water quality in the Appalachian region for decades and will continue to adversely affect these areas unless effective and comprehensive remedial actions can be designed and applied.

The U. S. Department of Energy National Energy Technology Lab's (NETL) Clean Water Team utilizes an airborne platform with four different technologies consisting of a multi-spectral scanner (MSS) equipped with dual infrared sensors, and three geophysical technologies: terrain conductivity, very low frequency, and magnetometry (Ackman et al., 2000). The airborne approach identifies potential problem areas over whole watershed areas 
in a short period of time and helps identify possible relationships between polluted areas that might otherwise be missed by limited surface investigations.

\subsection{Previous Research}

Traditionally, airborne geophysical surveys have been used for the detection of conductive ore bodies and geologic mapping. However, in recent years, studies have demonstrated the effectiveness of airborne geophysics and remote sensing for environmental purposes.

King and Hynes (1994) used geophysical methods to monitor acid mine drainage at the Sudbury Igneous Complex. High quality airborne geophysical data was acquired with a multi-coil, multi-frequency helicopter electromagnetic system over tailings areas, which are thought to be source areas of AMD seeps. The airborne data results indicated that anomalous areas coincided with the tailings. The airborne surveys were verified by groundbased geophysical surveys performed with Geonics EM-31 and EM-34 terrain conductivity instruments. Additionally, borehole electromagnetic surveys were conducted to locate the source of the anomalous conductivity within the tailings piles. The electromagnetic conductivity data was correlated with previously acquired resistivity data. The study showed that the combination of airborne and ground-based geophysical investigations characterize the three-dimensional distribution of acid-producing materials within the tailings piles.

Torgerson, et al. (2001) was successful in monitoring stream and river temperature using an airborne thermal infrared platform developed to measure spatially continuous patterns of water temperature in streams. High-resolution imagery was recorded for the streams and adjacent areas from a helicopter platform. The geo-referenced images made it possible to map large-scale changes in the stream temperatures and to identify fine details, 
which contribute to the stream's overall temperature. Thermal stratification in the stream and reflective long wave radiation are causes for erroneous measurements in remote sensing data. Ground surveys were performed to verify the results of the airborne remote sensing data. The airborne data were consistently within $\pm 0.5^{\circ} \mathrm{C}$ when compared to the groundbased results.

The US Department of Energy has used airborne and ground geophysical surveys to identify and map groundwater flow paths and recharge and discharge locations that may be related to acid mine drainage (AMD). Airborne surveys have been completed over the Yellow Creek Watershed Area, Sulphur Bank Mercury Mine, and Kettle Creek Basin.

The Yellow Creek watershed area is located in Hammondsville, OH. Thermal infrared data was collected over the Yellow Creek watershed area where an AMD "blowout" occurred in the stream (Mabie et al., 2001). The study used nighttime thermal infrared imagery to identify areas where groundwater discharges to the surface as mine discharges, seeps, and springs. A terrain conductivity survey was employed to map a contaminated surface and groundwater plume between a known mine adit, or mine shaft, and the North Fork of Yellow Creek to ensure that the AMD discharging from the adit was not the source of the "blowout" in the stream. The EM survey showed that the adit was probably not the source of contaminated water at the "blowout" area because both the surface water and groundwater from this mine entered the North Fork of Yellow Creek below the impacted area (Mabie, Hammack, Veloski, 2001).

Another study focused on the Sulphur Bank Mercury Mine, located in Clear Lake, California (Hammack and Mabie, 2002). Areas of high conductivity identified in the airborne electromagnetic conductivity survey results were corroborated with ground-based 
geophysical surveys. Anomalies identified in the waste rock dam were interpreted as flow paths for conductive, mercury-bearing water from the Herman Impoundment, a flooded open pit mine, into Clear Lake. Additionally, the airborne geophysical results were used to map fault zones, which may also act as conduits for groundwater flow (Hammack and Mabie, 2002).

Nighttime high-resolution airborne thermal infrared imagery data were collected over the Kettle Creek and Cooks Run watersheds, tributaries of the West Branch of the Susquehanna River. The purpose of this investigation was to evaluate the effectiveness of thermal infrared (TIR) data for identifying sources of acid mine drainage (AMD) from abandoned coal mines. Coal mining from the late 1800's resulted in many AMD sources from abandoned coal mines in the Lower Kettle Creek and Cooks Run Basin. Potential AMD sources were identified from airborne TIR data employing custom image processing algorithms and GIS data analysis. Based on field reconnaissance of TIR anomalies, $51 \%$ were classified as AMD (Sams, J. and Veloski, G, 2003, unpublished data).

\subsection{Purpose and Objectives}

The United States Department of Energy National Energy and Technology Laboratory's (NETL) Clean Water Team has conducted several airborne surveys of watersheds in northern West Virginia to detect potential pollution sources. The airborne approach provides a rapid reconnaissance of the geophysical characteristics of potential contamination sites (Ackman and Cohen, 1994). The airborne surveys are followed by surface geophysical surveys to better delineate the conductivity anomalies observed in the airborne data. The various ground-based geophysical methods that are used at ground survey locations include terrain conductivity, borehole geophysical surveys, and resistivity. 
The purpose of this research project is to investigate the significance of electromagnetic and thermal infrared anomalies observed in airborne surveys of the $\mathrm{T}$ and $\mathrm{T}$ Mine Complex located in Preston County, West Virginia (Figure 1). The airborne conductivity surveys were acquired using an electromagnetic system that utilizes five sets of horizontal coplanar coil-pairs with frequencies ranging from $390 \mathrm{~Hz}$ to $102,680 \mathrm{~Hz}$. Two bands of nighttime airborne thermal infrared imagery were acquired with spectral sensitivity range of $3-5 \mu \mathrm{m}$ and $8.5-12 \mu \mathrm{m}$, respectively. Electromagnetic and thermal anomalies observed in these data will be compared to mine maps in order to correlate the anomalous features with mine pools and ground water discharge points, which may represent acid mine drainage.

The study will use surface and borehole geophysics to corroborate the results of the airborne surveys and to provide higher resolution mapping of the areal extents of electromagnetic anomalies. While airborne surveys can provide a rapid reconnaissance of an area, ground-based surveys can provide high-resolution views of the anomalous features. The results of this study should help design efficient ground-based geophysical investigations to quickly survey areas and compare results between airborne and groundbased surveys.

Data manipulation includes a combination of forward and inverse modeling of results obtained from both the airborne and ground geophysical surveys and analysis of the thermal infrared data. The purpose of the modeling is to resolve the underground mine pool and the possible extent of acid mine waters. 


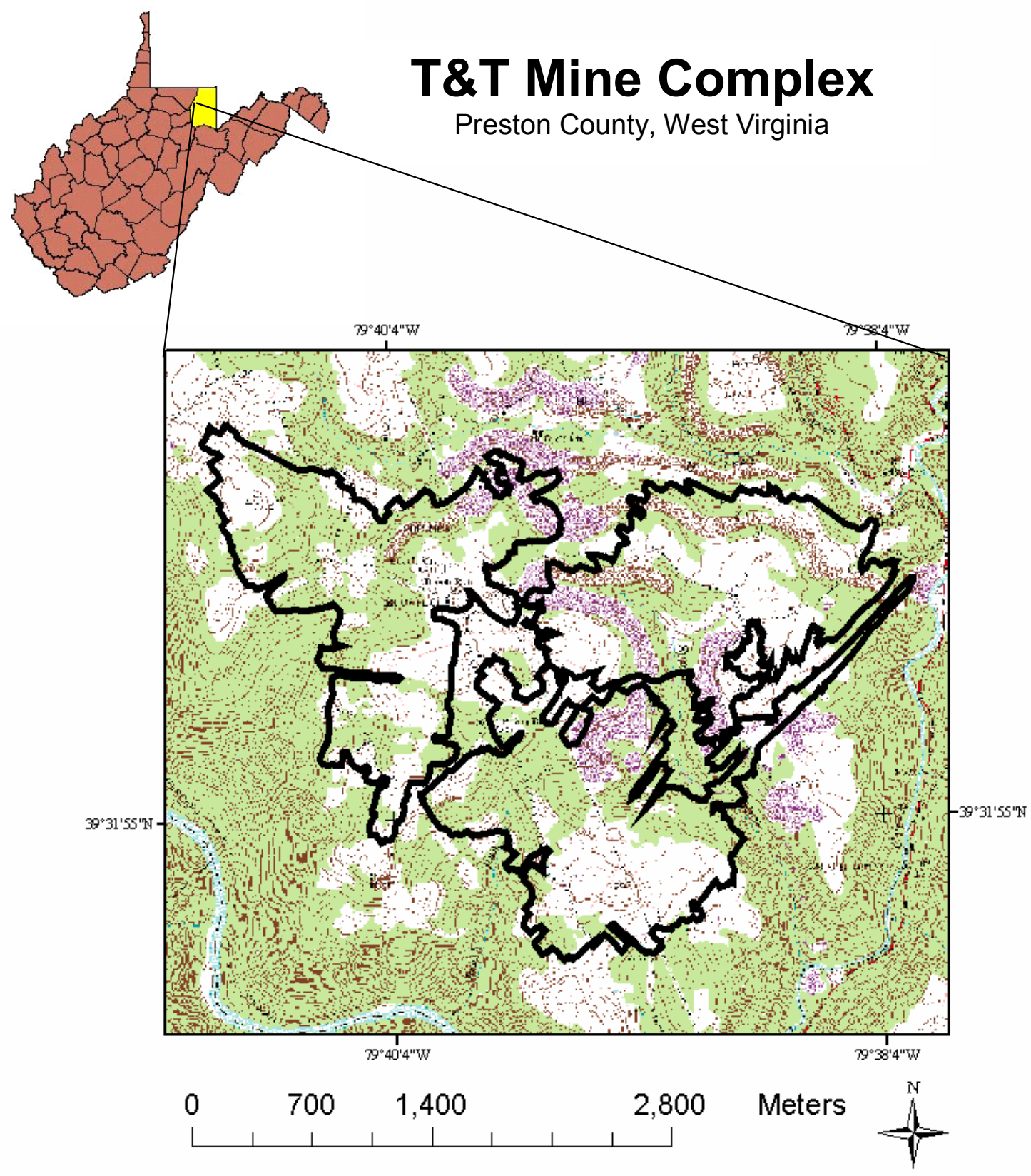

Figure 1: Location map of the T\&T Mine Complex, Preston County, WV. The mine complex is comprised of three underground room and pillar mines: T\&T \#1, T\&T \#2, and Ruthbell The underground mines are outlined in a solid black line overlain on a USGS Digital Raster Graphic. 


\subsection{Site Description}

The T\&T Mine Complex is located in near Albright, Preston County, West Virginia (Figure 1). The complex is comprised of three underground, room and pillar mines: T\&T \#1, T\&T \#2, and the Ruthbell Mine. The mines are situated in the Pennsylvanian Conemaugh Group and Allegheny Formation, and are located at a depth approximately 85-90 meters below the surface. The target coal seam was the Upper Freeport Coal, a multiple-bedded coal seam ranging in thickness from 0 to 3 meters, and marks the boundary between the Conemaugh Group and Allegheny Formation. A generalized stratigraphic column for the mine complex is shown in Figure 2. Figure 3 is a geologic map of Preston County and shows that the mine complex is situated on the southeast limb of the Preston Anticline. The Preston Anticline strikes northeast-southwest and plunges to the northeast. The overburden consists of massive sandstones, interbeds of limestone and shale, and two significant coal beds, the Harlem Coal and the Bakerstown Coal.

Three coal beds were surface mined within the study area. The Upper Freeport Coal was surface mined near the northern study area boundary. The Bakerstown Coal, a 1.5 meter thick coal seam within the Conemaugh Group that occurs about 54 meters above the Upper Freeport Coal, was surface mined along the upper reaches of Sypolt Run and along the northern boundary of the study area. The Harlem Coal, which is about 0.6 meters thick and occurs about 15 meters above the Bakerstown Coal, may have been surface mined in limited areas.

Once the underground mining was complete, the mines were allowed to flood with water. Figure 4 depicts the flooded portions of the mine (orange polygons) and the surface mined areas (red polygons) within the study area. Effluent AMD discharge from the mine 
complex has a $\mathrm{pH}<3.0$. Presently, the AMD effluent is being treated by the West Virginia Department of Environmental Protection.

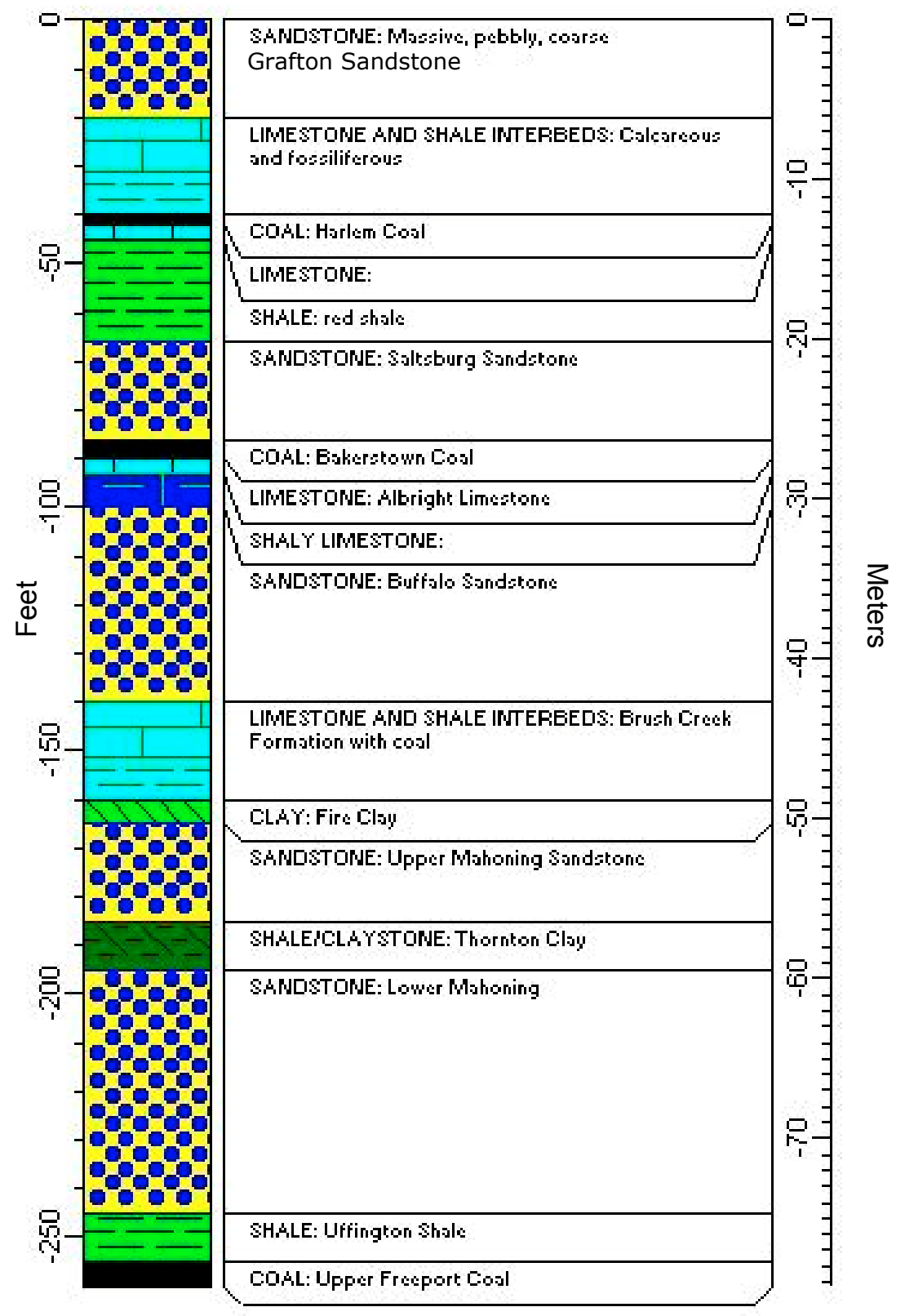

Figure 2: A generalized stratigraphic column for the T\&T Mine Complex. The mine is situated in the Upper Freeport Coal. Data compiled from well borings in the study area. 

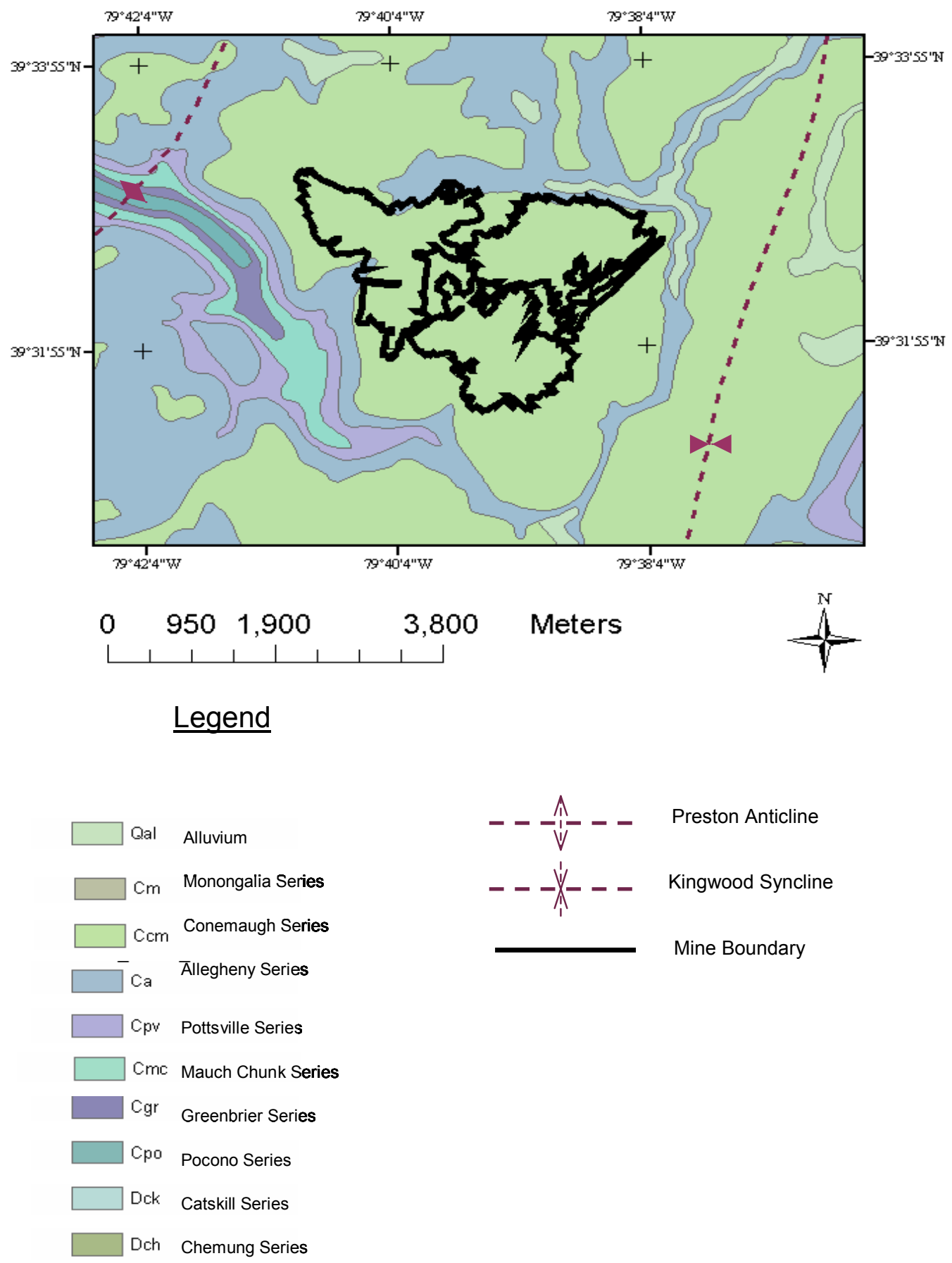

Figure 3: Geologic map of study area. The mine complex is situated on the southeast limb of the Preston anticline. 


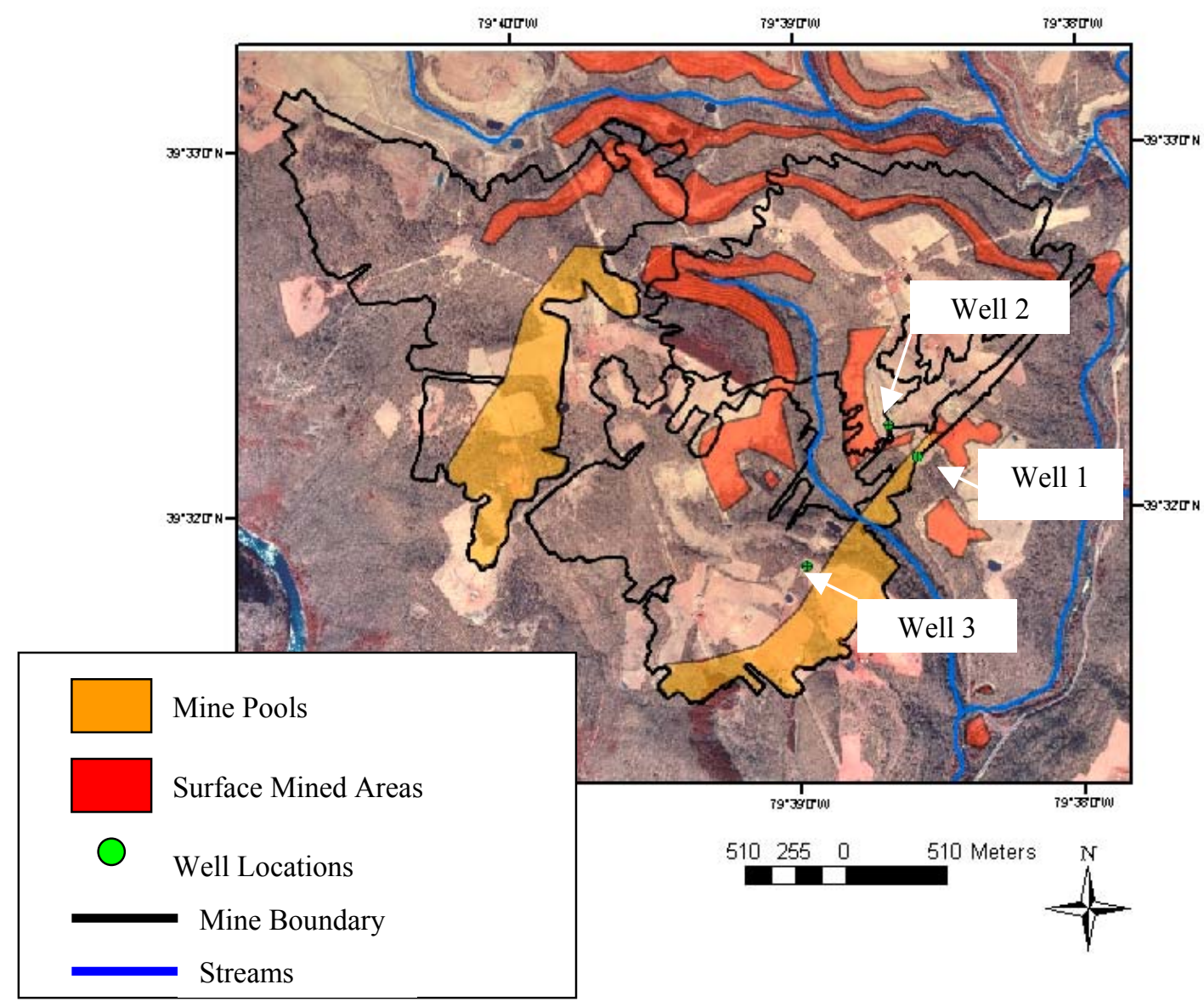

Figure 4: Well locations available for borehole geophysical surveys displayed on a false color digital orthophoto quarter quadrangle (DOQQ). The well data provided control for ground-based surveys. 


\section{CHAPTER 2 - Review of Geophysical and Remote Sensing Methods for Environmental Applications}

\subsection{Terrain Conductivity}

Conductivity varies within the earth and is controlled by the rocks and soil that make up the subsurface. Factors controlling the conductivity of a given area are: porosity, moisture content, dissolved electrolyte content, temperature and phase state of pore water, and the amount and composition of colloids (McNeill, 1980-a).

The terrain conductivity method uses a transmitter coil that produces a primary electromagnetic wave that travels through the ground. The alternating electric current produces an alternating magnetic field that induces current flow through the earth. Current flow in the receiver coil is induced in response to the electromagnetic fields generated by the transmitter and the induced secondary ground currents.

The strength of the secondary field is dependent on intercoil spacing, frequency of the primary field, and ground conductivity. As described by McNeill, there is a simple relationship between the primary and secondary fields when the operation frequency of the terrain conductivity meter is confined to the constraints of a low induction number. The terrain conductivity has a linear relationship with the ratio of the primary and secondary magnetic fields. McNeill (1980-b) gives the relationship:

$$
{\underline{\mathrm{H}_{\underline{s}}}}_{\underline{\mathrm{p}}}=\frac{i \omega \underline{\mu}_{0} \underline{\sigma \mathrm{s}^{2}}}{4}
$$

Where $\mathrm{H}_{\mathrm{s}}$ is the secondary magnetic field at the receiver coil

$\mathrm{H}_{\mathrm{p}}$ is the primary magnetic field at the receiver coil

$\omega$ is equal to $2 \pi f$ 
$\mathrm{f}$ is the frequency of alternating current in transmitter coil

$\mu_{0}$ is permeability of free space

$\sigma$ is ground conductivity

$\mathrm{s}$ is the intercoil spacing

$\mathrm{i}$ is square root of -1 .

The instrument directly measures the primary and secondary fields and the ratio is known; therefore, the apparent conductivity is also known (McNeill, 1980-b).

A low induction number makes the general relationship between the ratio of the primary and secondary and terrain conductivity possible. The induction number, $\mathrm{B}$, is dependent on the intercoil spacing and the skin depth:

$$
\mathrm{B}=\underline{\mathrm{s}}
$$

Where $\mathrm{s}$ is the intercoil spacing and $\delta$ is the skin depth (McNeill, 1980-b). The skin depth is described as the depth at which the amplitude of the electromagnetic field drops to 1/e of the source amplitude (e being the natural base). Skin depth is a function of the operating frequency and the ground conductivity (McNeill, 1980). The skin depth is given by the following relationship:

$$
\delta=500(1 / \sigma f)^{1 / 2}
$$

As implied by this relationship, increases in ground conductivity and frequency will decrease the skin depth, and therefore, decrease the depth of investigation.

The average conductivity, as calculated from the induction logs at the mine complex, is approximately 20 millimhos per meter $(\mathrm{mmhos} / \mathrm{m})$. Using equation 3 , the skin depths for the various airborne frequencies were calculated (Table 1). 
Table 1: Skin depths for various frequencies used in the airborne EM survey.

\begin{tabular}{|c|c|}
\hline $\begin{array}{c}\text { Frequency } \\
\text { (Hz) }\end{array}$ & Skin Depth (m) \\
\hline 102680 & 11.03 \\
\hline 25800 & 22.01 \\
\hline 6254 & 44.71 \\
\hline 1555 & 89.66 \\
\hline 390 & 179.03 \\
\hline
\end{tabular}

In general, the relationship of the peak amplitude of an oscillating electromagnetic field at a distance $r$ from the source will drop off is given by:

$$
A_{r}=A_{s} e^{-\alpha r}
$$

Where $A_{r}$ is the peak amplitude and $\alpha$ is the absorption coefficient (McNeill, 1980-b).

The absorption coefficient varies in proportion to the frequency of the electromagnetic wave such that higher frequencies are attenuated more than lower frequencies over the same distance. Therefore, to obtain a greater exploration depth, a lower frequency must be used.

The EM34 allows three different coil spacings and frequencies. The larger the intercoil spacing and lower operating frequencies allow for a greater depth of penetration. Generally, the effective depth of exploration is greater when the instrument operates in the vertical dipole field (Figure 5). The three different coil spacings and operating frequencies are 10 meters, 20 meters, and 40 meters, and $6400 \mathrm{~Hz}, 1600 \mathrm{~Hz}$, and 400Hz, respectively. The effective exploration depth in the horizontal dipole field is $7.5 \mathrm{~m}, 15 \mathrm{~m}$, and $30 \mathrm{~m}$, respectively; the effective exploration depth in the vertical dipole field is $15 \mathrm{~m}, 30 \mathrm{~m}$, and 60 $\mathrm{m}$, respectively (McNeill, 1980-b). For this survey, the 10-m, $20 \mathrm{~m}$ and 40-m intercoil spacings were used for EM-34 soundings. 


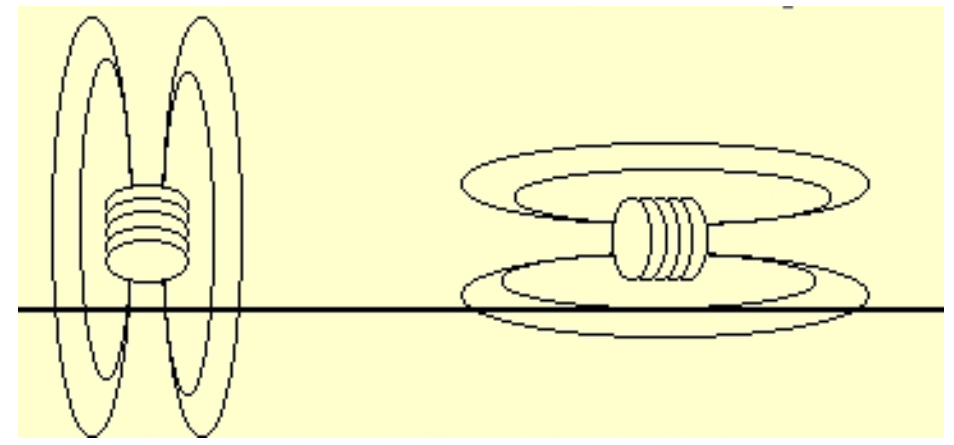

Figure 5: The vertical and horizontal dipole orientations determine the effective exploration depth

The apparent conductivity measured at the surface by the conductivity meter is a composite response of the contributions from the entire subsurface medium. The relative contribution of a given interval at arbitrary depths to measure terrain conductivity is defined by the relative response function $\Phi(\mathrm{z})$, where $\mathrm{z}$ is the depth divided by the intercoil spacing and $\Phi(\mathrm{z})$ quantifies the relative contribution to the secondary magnetic field arising from a thin layer at any depth $\mathrm{z}$ (McNeill, 1980-b). Figure 6 depicts the relative response function for the vertical and horizontal dipole modes of operation. Note how each dipole responds to materials at depth. The horizontal dipole is much more sensitive to near surface materials and drops off significantly at depth. The vertical dipole exhibits little or no response to near surface materials, peaks at $\mathrm{z}=0.5$, and is more responsive to materials at depth.

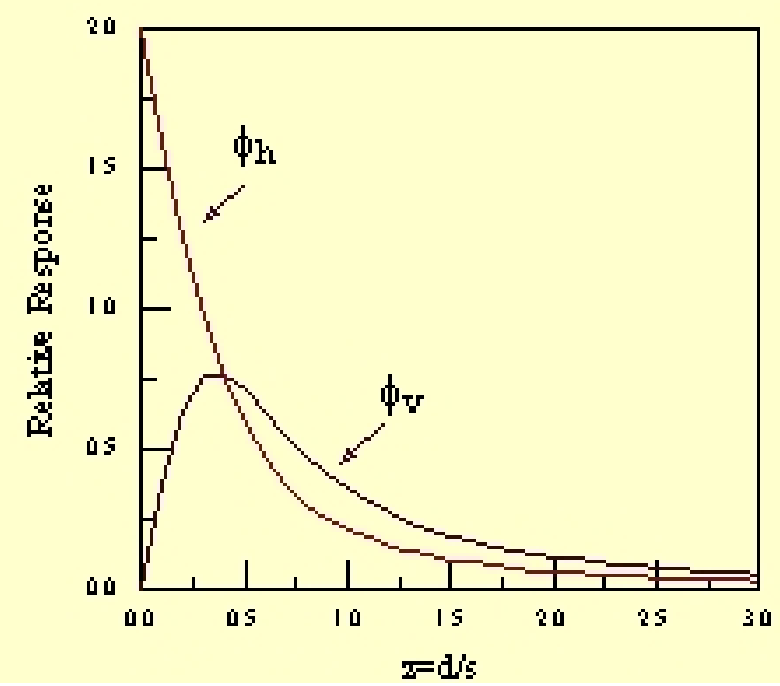

Figure 6: A comparison of the relative response for the vertical and horizontal dipoles (McNeill, 1980-b) 
The relative response function describes the relative sensitivity of the horizontal or vertical coil configurations to materials at various depths. From the relative response function, the cumulative response function can be derived, which defines the relative contribution of the apparent conductivity from all material below a depth of $\mathrm{z}$ (McNeill, 1980-b), given by:

$$
\mathrm{R}_{\mathrm{V}}(\mathrm{z})=\int_{\mathrm{z}}^{4} \Phi_{\mathrm{V}}(\mathrm{z}) \mathrm{dz}
$$

Figure 7 illustrates the cumulative response versus depth for the horizontal and vertical dipoles. The apparent conductivity is given by the relationship in which the dependence of the apparent conductivity on intercoil spacing is imbedded in the values of $z$ (McNeill, 1980-b):

$$
\sigma_{\mathrm{a}}=\sigma_{1}\left[1-\mathrm{R}\left(\mathrm{z}_{1}\right)\right]+\sigma_{2} \mathrm{R}\left(\mathrm{z}_{2}\right)
$$

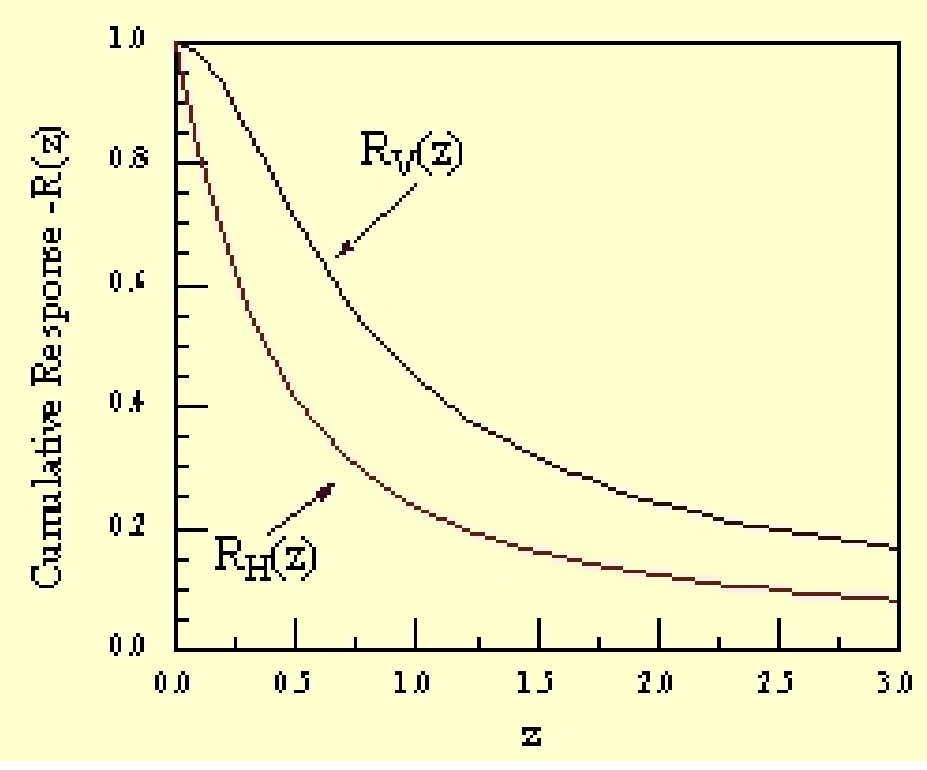

Figure 7: The cumulative response versus depth for each dipole (McNeill, 1980-b) 
Figure 8 depicts a layered-earth model in which equation 6 would be used to determine the apparent conductivity. The apparent conductivity is the sum total of all contributions from all layers; therefore, the areas under the relative response curves can be expressed as a difference between cumulative response functions.

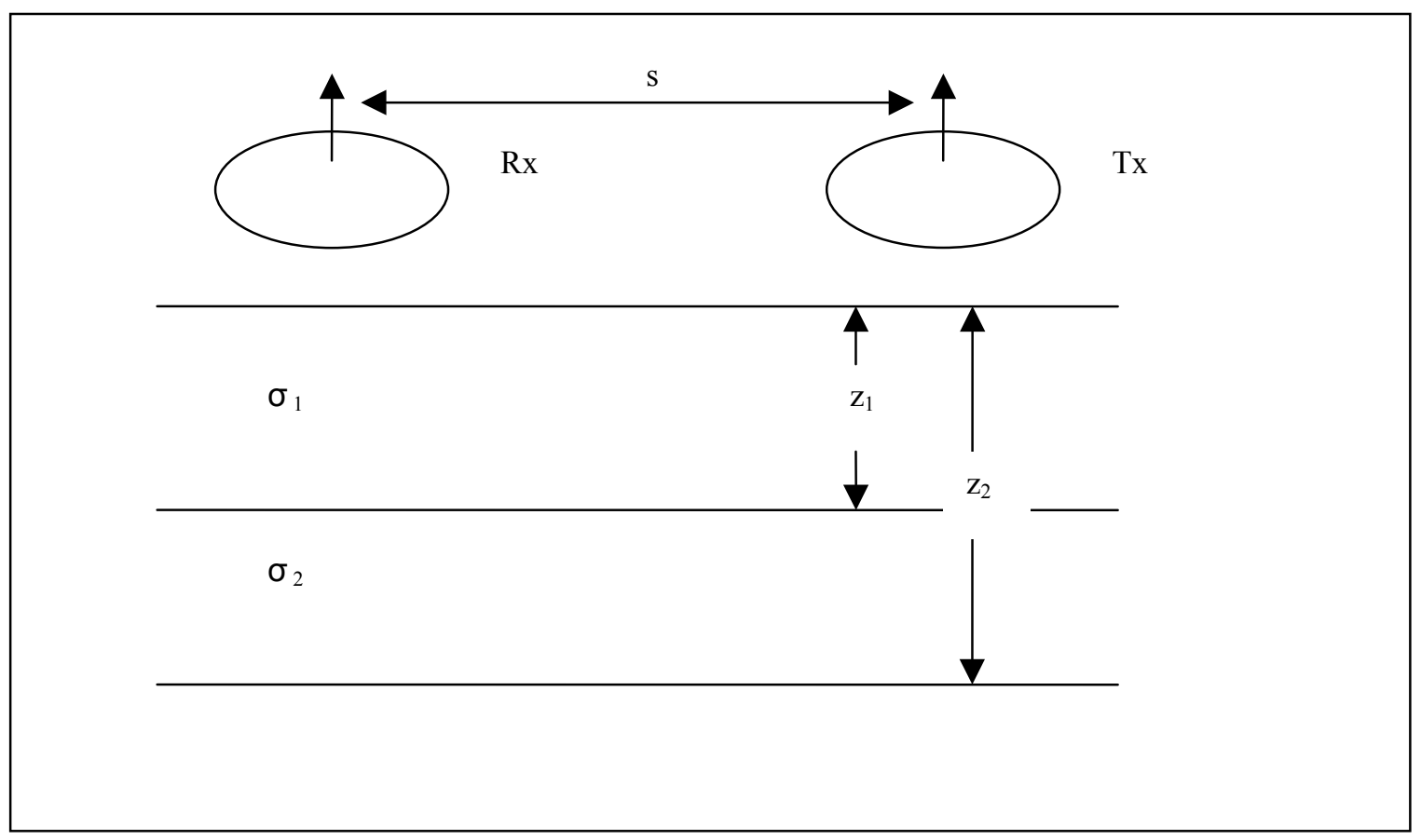

Figure 8: Layered-earth model. Rx represents the receiving coil and Tx represents the transmitting coil. Equation 6 can be used to determine the apparent conductivity.

\subsection{Airborne Electromagnetic System}

Fugro Airborne Surveys performed the helicopter electromagnetic survey (HEM) survey of the T\&T Mine Complex on November 4, 1999 using the DIGHEM ${ }^{\text {VRES }}$ electromagnetic data acquisition system. The pilot and Bell 412 helicopter were provided by DOE's Remote Sensing Laboratory, which is operated by Bechtel, Nevada. The DIGHEM $^{\text {VRES }}$ system consists of five coplanar coil pairs operating at frequencies of $390 \mathrm{~Hz}$, 1,555 Hz, 6,254 Hz, 25,800 Hz, and 102,680 Hz (Figure 9). The coil separation for all frequencies was 7.86 meters. The system yields in-phase and quadrature data (Fugro, 2000). 
A complete description of the DIGHEM ${ }^{\mathrm{VRES}}$ system specifications and applications can be accessed at http://www.fugroairborne.com/ProductsServices/airborne/em/dighem/dighem.shtml.

\section{DIGHEMN RES-BIRD COIL CONFIGURATION}

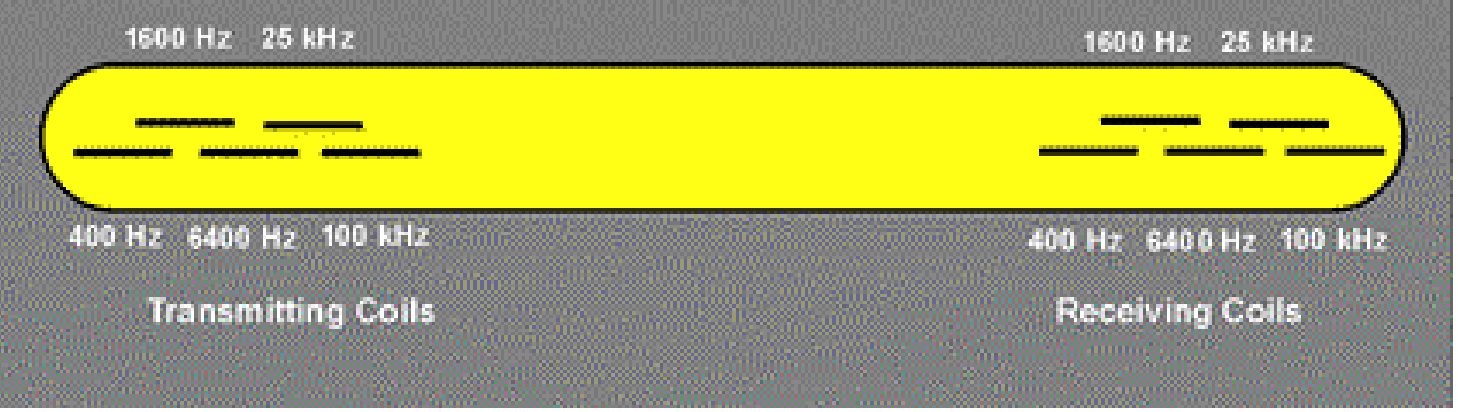

Figure 9: A schematic of the DighemVRES coil configuration. The coil configuration consists of 5 pairs of coplanar coils ranging in frequency from $390 \mathrm{~Hz}$ to $102,680 \mathrm{~Hz}$.

The HEM survey of the T\&T Mine Complex was flown on east-west traverse lines with a line separation of 100 meters. The average sensor to ground height was about 55 meters, 25 meters higher than the desired sensor height of 30 meters. The high sensor height was the result of an inexperienced pilot, moderately rugged terrain, and the need to clear power lines. The excessive sensor height decreased the amplitude of secondary signals from the ground and resulted in noisy data.

\subsection{Resistivity Methods}

Electrical resistivity methods require that a direct current be injected into the ground and the ground resistivity is measured as a potential difference between two electrodes. In comparison, terrain conductivity methods (the inverse of resistivity) use induced current flow to measure electrical properties of the subsurface. The resistivity of the ground will 
correspond to true resistivity if the ground is homogenous and isotropic (Yazicigil and Sendlein, 1982). However, this is seldom the case. The measured resistivity is apparent resistivity, given by the equation (Burger, 1992):

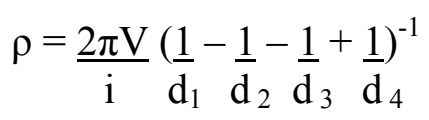

In an electrical resistivity survey, a direct current of intensity, I, is injected into the ground via a pair of current electrodes. The potential drop, $\Delta \mathrm{V}$, is measured across the potential electrodes. Several electrode array configurations are used for resistivity measurements (Stoller and Roux, 1975). For the purpose of this study, the dipole-dipole array (Figure 10) and the Wenner array (Figure 11) were used to perform horizontal profiling and soundings over areas adjacent to well locations using the Super Sting R8/IP, by Advanced Geosciences, Inc.

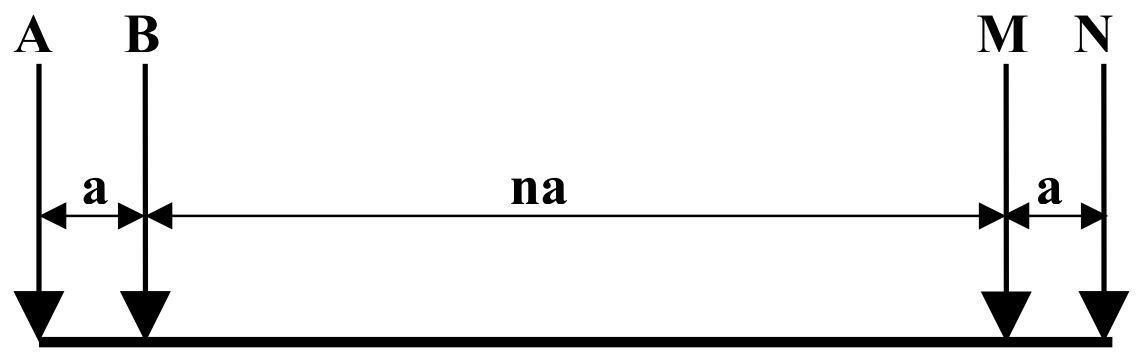

Figure 10: Dipole-dipole array is arranged such that two dipoles are formed by $\mathrm{AB}$ and $\mathrm{MN}$, respectively. The electrode spacing is 4 meters

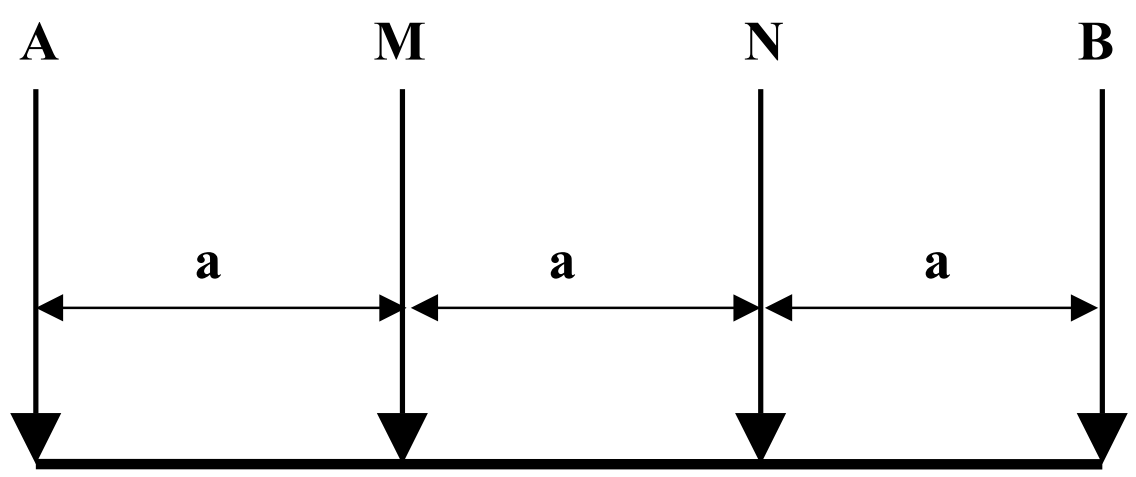

Figure 11: The Wenner array. The electrodes are equally spaced at 4 meters. 
The dipole-dipole is a common geometry for resistivity surveys. The potential electrodes and current electrodes function independently as dipoles to provide good lateral resolution. In a survey, the potential electrodes are placed relative to the current electrodes. The Wenner array places all electrodes at an equal distance from each other. In a survey, all of the electrodes are moved along a profile, but the spacing between the electrodes remains the same (Burger, 1992).

Apparent resistivity can be studied in two ways: electrical soundings and horizontal profiling. The aim of an electrical sounding is to attempt to map the underground electrical resistivity by means of surface measurements. A deduction of variation of electrical resistivity with depth at any given point on the earth's surface can be made, regardless of the configuration. The further away from a current source the measurement is made, the greater the depth of electrical penetration (Yazicigil and Sendlein, 1982).

Horizontal profiling is used to detect lateral variations in the subsurface. A fixed electrode spacing is chosen and the whole array is moved along a profile as each measurement is made (Yazicigil and Sendlein, 1982). The combined methods repeat the horizontal profiling method at wider electrode spacings to obtain a series of profiles that can be presented as a pseudo-section.

\subsection{Time Domain Electromagnetic Induction Methods}

Time domain electromagnetic (TDEM) induction methods have been traditionally used for geothermal exploration and deep structural mapping. More recently, TDEM methods have been used for mining exploration, engineering, and environmental purposes (Tasci and Jordan, no date). 
TDEM methods are those in which time-dependent magnetic fields are created by inducing square waves of current through a grounded wire source. Passing a step current through the cable generates an electromagnetic field. There are two parts to this magnetic field; one from the current flowing through the cable, and the other from the return currents flowing through the Earth (Keller, 1997).

The time-varying electromagnetic field generated by the transmitter coil induces a secondary time-varying eddy current and magnetic field in subsurface intervals (Figure 12). This secondary magnetic field is measured at the site. Its intensity and phase provide information about subsurface resistivity variations beneath the coil (Keller, 1997). For this study, the PROTEM-47, manufactured by Geonics Limited, was used with a 40x40 meter transmitter coil.

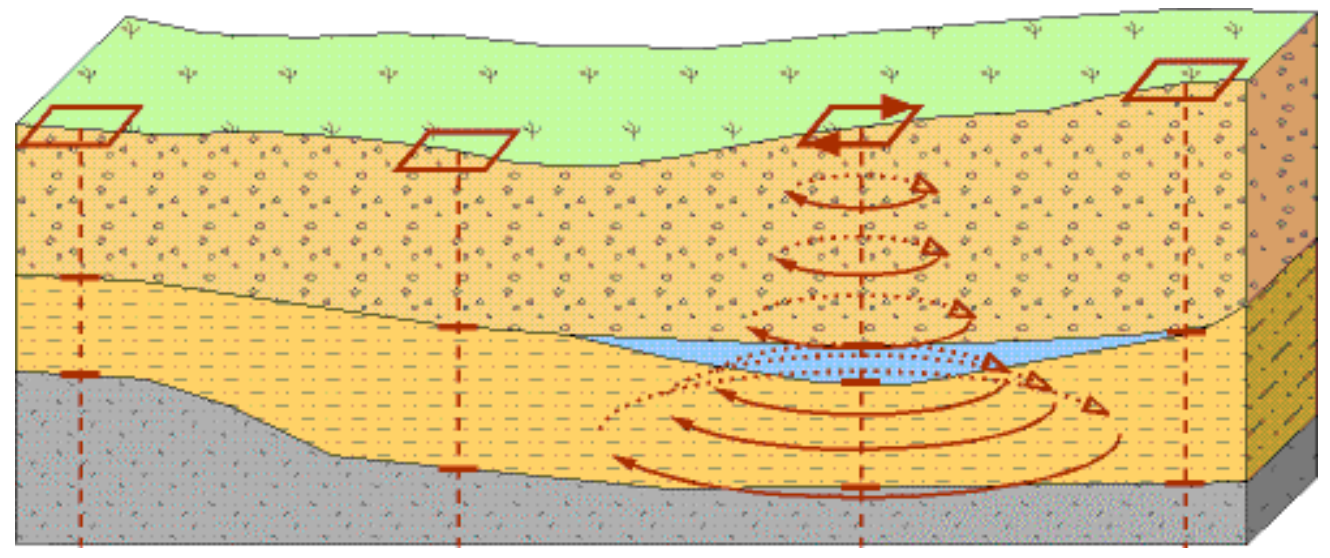

Figure 12: Square waves are induced into the ground and the energy creates eddies. This, in turn, creates a secondary magnetic field, which is measured at the earth's surface. Source: Northwest Geophysical Associates (www.nga.com).

\subsection{Borehole Geophysics}

Borehole geophysical logging includes all methods for lowering a sensing device into a cased or uncased borehole to record a physical, chemical, electrical, or radioactive property 
along the well bore. Traditionally used by the petroleum industry, the properties useful for determining oil and gas prospects can also be used in environmental and hydrological investigations associated with ground water pollution.

Three wells on the study site were available for borehole geophysics (see Figure 4). Each well was drilled into a known mine void by Coastal Coal Company in order to inject a neutralizing lime slurry into the flooded portion of the underground mine. The mine is situated on the east limb of a plunging anticline; the wells were drilled up-gradient of inferred mine pools for the lime slurry injection. Each well was drilled to an approximate depth of 80 meters below the surface. The suite of geophysical logs completed in each well includes an induction log to measure electrical conductivity, and neutron, natural gamma, and gamma-gamma logs.

Neutron logs use a radioactive source that releases neutrons into a formation. The neutrons cause formations to emit gamma rays which are proportional to hydrogen content. The gamma radiation is recorded by the logging instrument. Neutron logs are often used to determine porosity, water content, and moisture content within a formation (Keys, 1988).

Natural gamma logs record the amount of naturally occurring gamma radiation in the borehole vicinity. Clay-bearing rocks naturally emit a high amount of gamma radiation due the abundance of potassium in clays and micas (Keys, 1988).

The gamma-gamma log, or density log, measures density through gamma radiation. The logging tool emits gamma radiation and records the amount of gamma radiation that returns from the formation surrounding the borehole area (Keys, 1988). The logs are calibrated such that bulk density is calculated. 


\subsection{Thermal Infrared Imagery}

Temperature can be described two ways: kinetic temperature or radiant temperature. Kinetic temperature is the internal manifestation of the average energy of the molecules which make up the body. Radiant temperature can be described as an object's external manifestation of molecular energy states. It is the external manifestation of an object's energy state that is remotely sensed (Lillesand and Kiefer, 2000).

There are spectral regions where the atmosphere conditions such as the amount of water vapor, carbon dioxide, and ozone can absorb solar radiation and limit remote sensing data acquisition (Figure 13). The wavelength ranges where the atmosphere is particularly transmissive of energy are referred to as atmospheric windows (Lillesand and Kiefer, 2000). Note that these windows occur at 3-5 $\mu \mathrm{m}$ and 8-14 $\mu \mathrm{m}$.

The warmer an objects is, the shorter the dominant emissive radiation wavelength. For this reason, the $3-5 \mu \mathrm{m}$ atmospheric window is often used for mapping very hot objects such as forest fires. On the other hand, the $8.5-12.5 \mu \mathrm{m}$ range is interesting because it not only occurs in an atmospheric window, but also at the peak of energy emissions for most surface features. The average ambient temperature of the surface features occurs at approximately $9.7 \mu \mathrm{m}$, making the $8.5-12.5 \mu \mathrm{m}$ very useful mapping earth surfaces (Lillesand and Kiefer, 2000). 


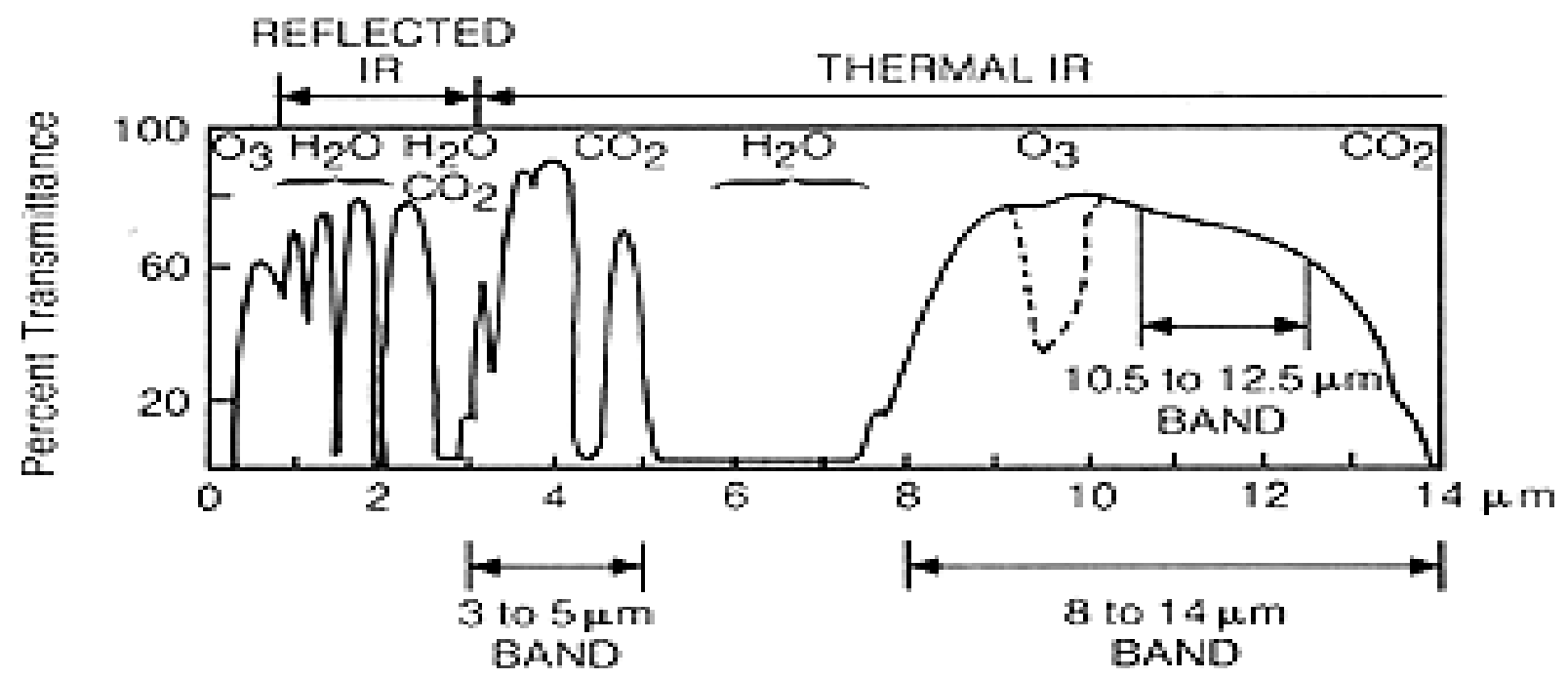

Figure 13: Atmospheric absorption of the wavelength range $0-15 \mu \mathrm{m}$. Note the atmospheric windows at 3-5 $\mu \mathrm{m}$ and 8-14 $\mu \mathrm{m}$ (Lillesand and Kiefer, 2000).

It should be noted that for most mapping situations where thermal imagery is utilized, such as the T\&T Mine Complex survey, the TIR data qualitative in nature. The calibration of the imagery to kinetic temperatures is not necessary, but rather it is the relative difference in temperature between objects that are of interest.

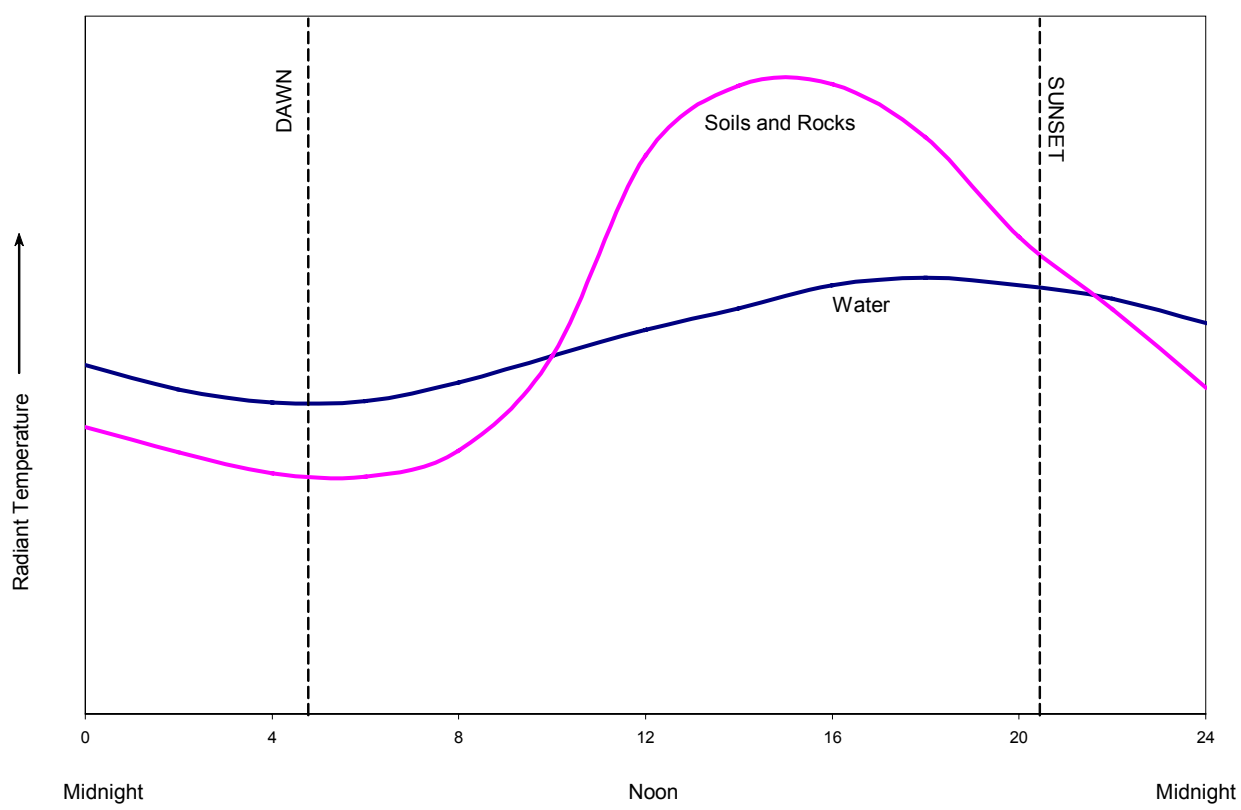

Figure 14: Generalized diurnal radiant temperature variation (Lillesand and Kiefer, 2000). 
Diurnal variations must be considered when acquiring thermal data. The comparison between the diurnal temperatures of water with that of soils and rock is shown in Figure 14. Note that the highest contrast between the ground and water occurs a few hours past solar noon and cooling takes place thereafter. Nighttime imagery is preferred because daylight data is dominated by variations in solar heating due to topography. The temperature curve for water is quite distinctive because the diurnal temperature range of water is very small compared to the ground temperature range, and water reaches its maximum temperature at a delayed time compared to the other materials. It can be concluded from the graph that the ground surface temperature is higher during the day and lower during the night than water temperature. The two points where the line crosses are called crossovers and they indicate no difference between the ground surface temperature and the water temperatures (Lillesand and Kiefer, 2000).

Two channels of nighttime thermal infrared imagery (TIR) were acquired at the T\&T Mine Complex as part of a survey of the Muddy Creek/Roaring Creek Watershed. The thermal sensor was a Daedalus AADS 1268 multi-spectral line scanner (MSS) coupled to a position and orientation system (POS). The MSS was configured for nighttime thermal operation with a spectral sensitivity range of $3-5 \mu \mathrm{m}$ (band 1) and $8.5-12.5 \mu \mathrm{m}$ (band 2). A GPS navigation system was used to plot the planned survey route. A minimum $30 \%$ overlap was specified between adjacent flight lines. The POS consisted of a Litton LN-200 inertial measurement unit (IMU), which provided trajectory data that was used to record orientation of the sensor head on the MSS. This instrument configuration allows data to be geo-rectified for distortions brought about by aircraft attitude (pitch, roll, and yaw) (Brewster, 1999). The 
data is corrected for geometric distortion using a combination of inertial measurements and Differential Global Positioning System (DGPS) navigation data collected in the air. The final corrected positional accuracy was found to be approximately \pm 1 meter. The data were also radiometrically corrected.

The thermal data were acquired between 3:00 am and 6:00 am to ensure optimal thermal contrast between cold surface water and warmer ground water from mine discharges, seeps, and springs. This time window allows objects heated by sunlight during the day to reach temperature equilibrium with the surroundings. 


\section{CHAPTER 3 - Modeling Results and Discussion}

\subsection{Borehole Geophysics}

Three wells were available to perform borehole geophysical surveys. The suite of geophysical logs completed in each well included induction, gamma-gamma, natural gamma, and neutron. The results of the induction logs are shown in Figure 15. In order to determine a starting model for the terrain conductivity modeling, the induction logs were averaged into geoelectric layers, which are not necessarily geologic layers (Keller and Frischknecht, 1966). As defined by Keller and Frischknecht (1966), a geoelectric layer is bounded by changes in electrical properties of the rocks and can contain many geologic layers or reside inside a single geologic layer. The geoelectric layered models contain layers of relatively similar electrical conductivity, not constant geology as the geology is more complicated than models in this project can represent.

The results of the induction logs are blocked into intervals of similar conductivity. In order to determine where boundaries should be placed to make a multi-layered conductivity model, the cumulative conductance is calculated and plotted against depth for each well (Stoyer, 1998). Cumulative conductance is calculated by summing the longitudinal conductance of each of the many thin layers from the well log and is calculated by dividing resistance $(\rho)$ of each layer by layer thickness $(h)$ :

$$
\mathrm{S}_{\text {cum }}=\sum \mathrm{h}_{\mathrm{i}} / \rho_{\mathrm{i}}
$$



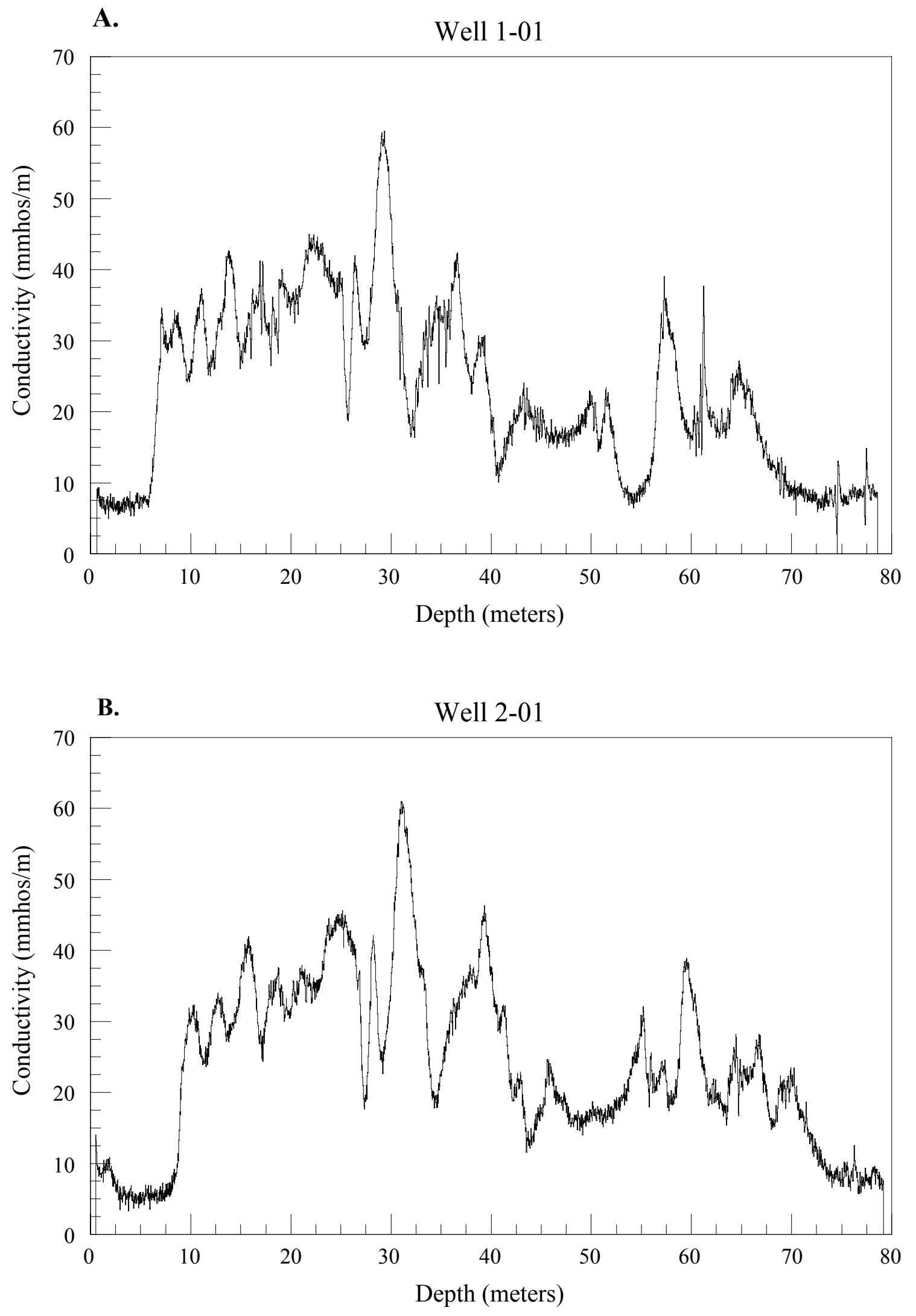


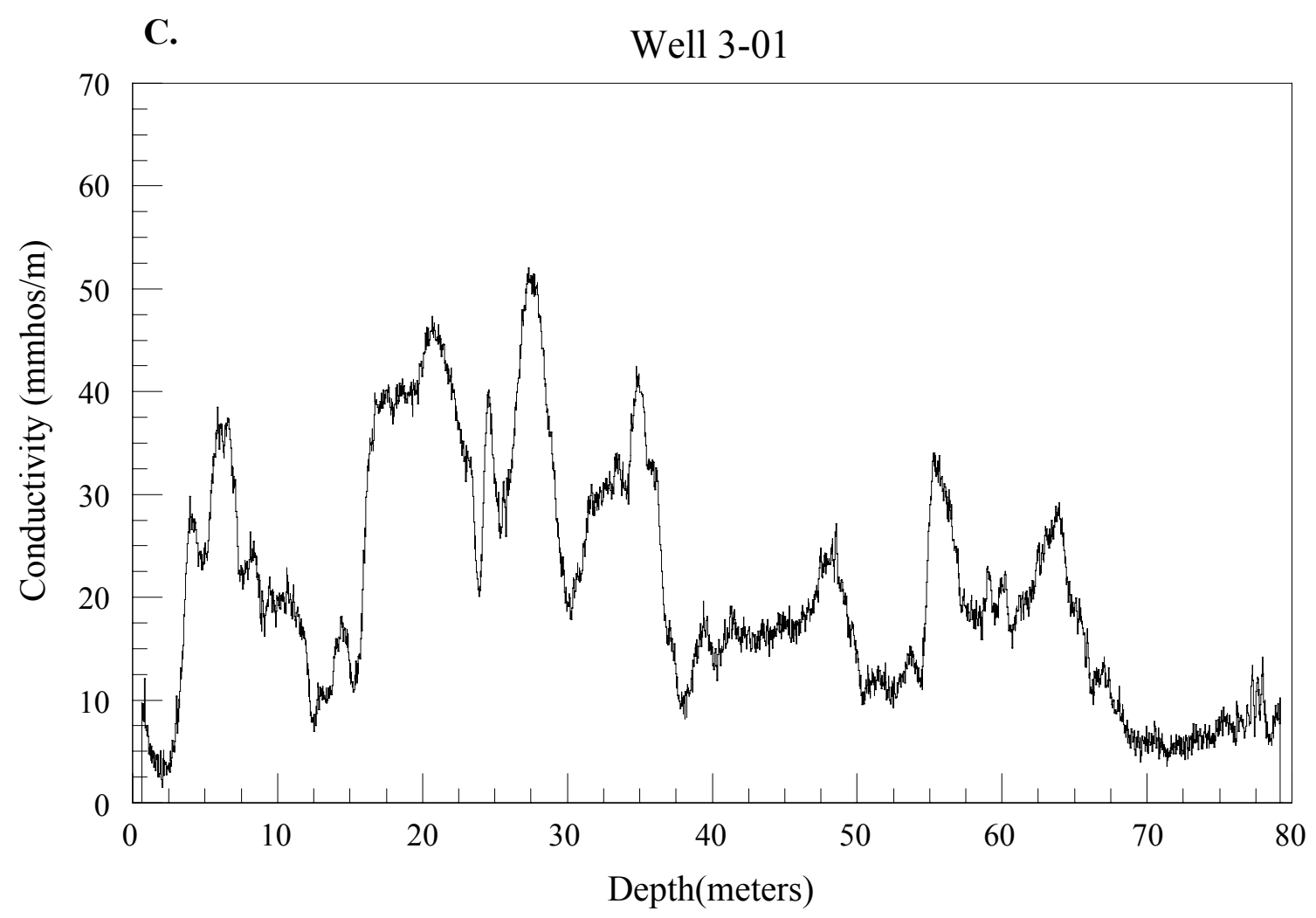

Figure 15 A, B, C: The induction logs for Wells 1-01, 2-01, 3-01 at the T\&T Mine Complex. Each well was logged to an approximate depth of 80 meters.

Figure 16 shows the plots of the cumulative conductance versus depth for each of the three wells. The shallow slopes indicate areas of high conductivity, while steep slopes are indicative of areas of low conductivity. A change in the slope of the lines indicates a geoelectric boundary. 

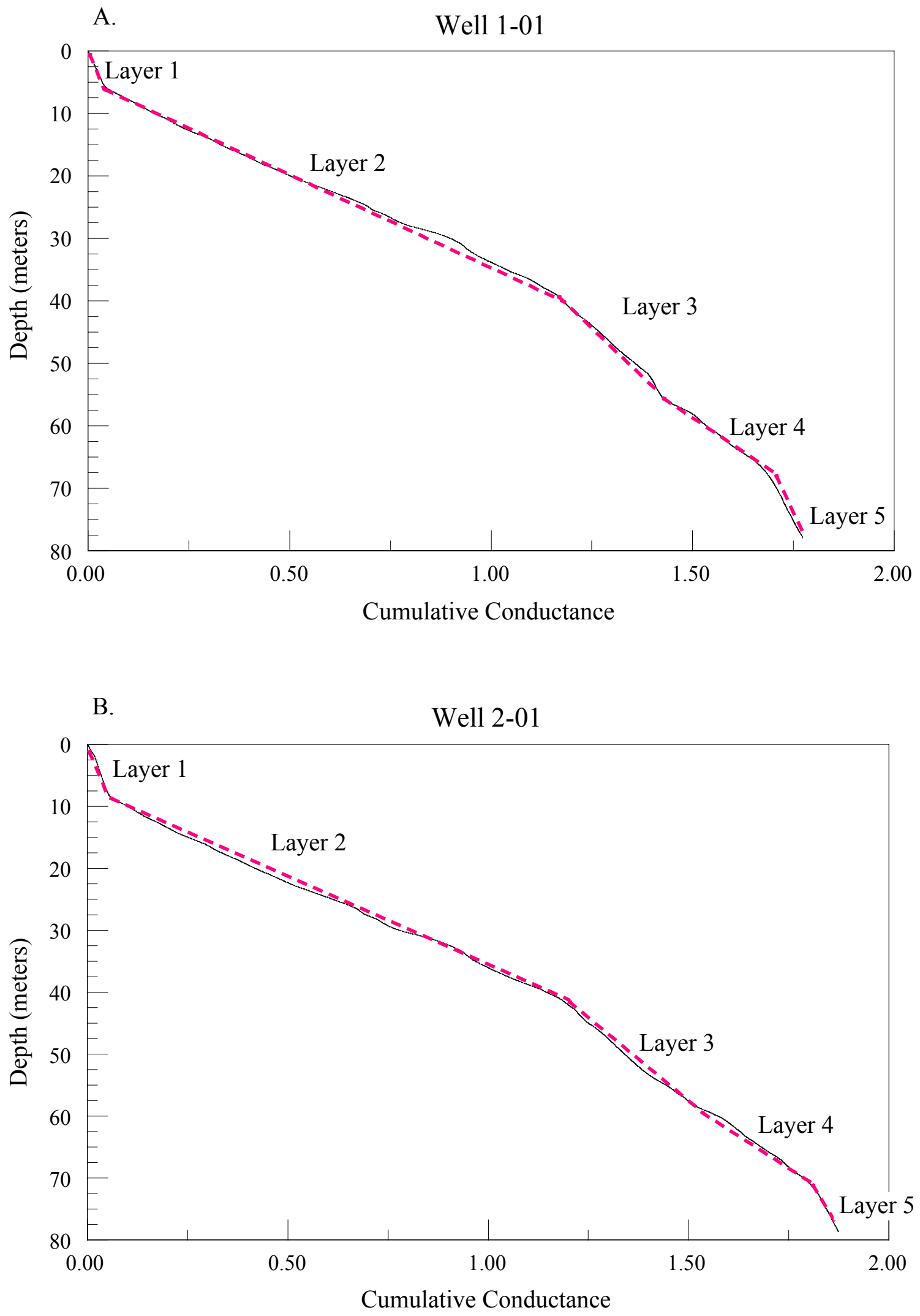


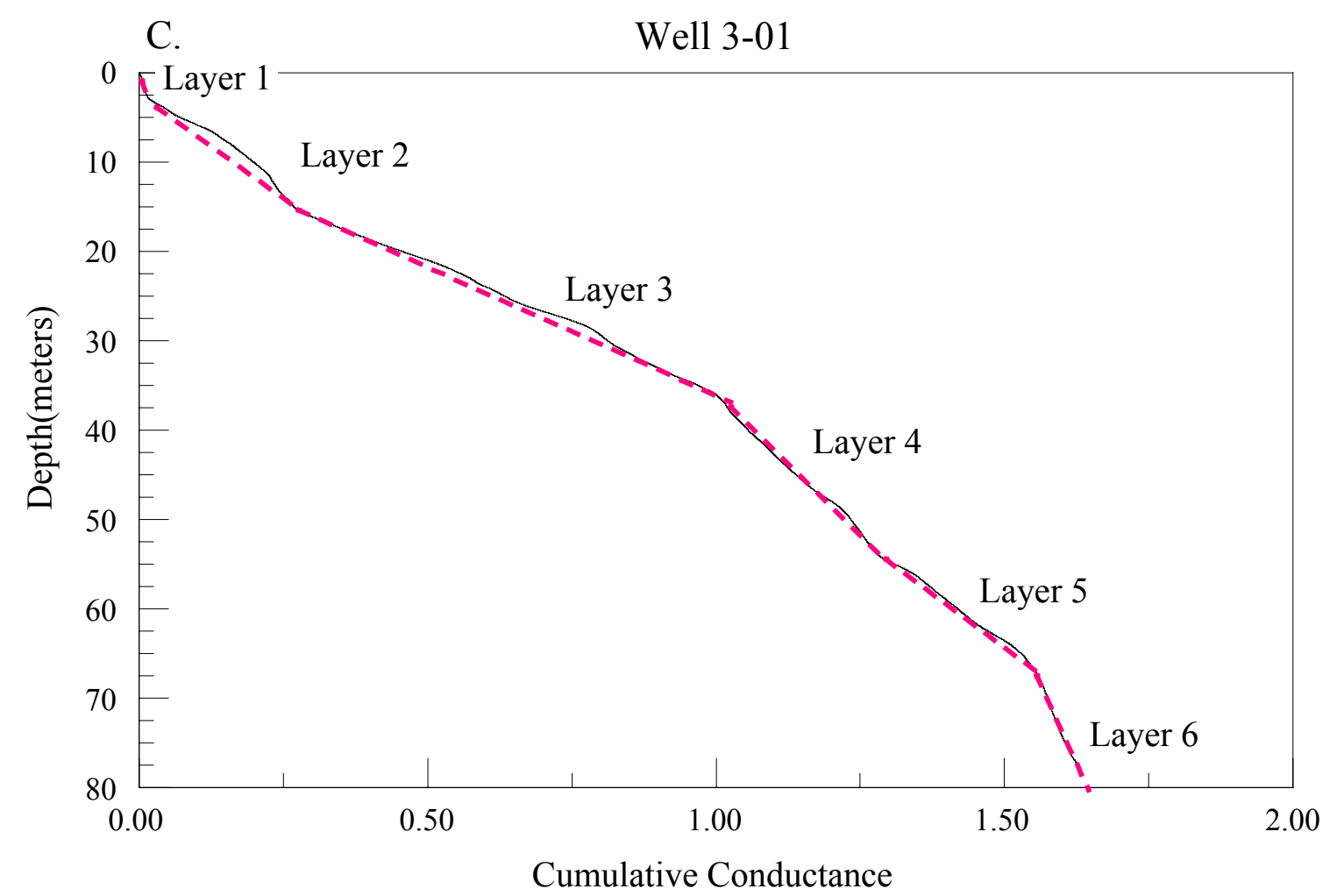

Figure 16 A, B, C: Plots of cumulative conductance versus depth for each well. A change in the slope of the line changes indicated changes in geoelectric layers.

The model layers are easily determined by the changes in slope. Well 1-01 and Well 2-01 can be divided into 5 layers, with breaks at $7 \mathrm{~m}, 40 \mathrm{~m}, 56 \mathrm{~m}, 67 \mathrm{~m}$, and $8.9 \mathrm{~m}, 42 \mathrm{~m}, 54 \mathrm{~m}$, $71 \mathrm{~m}$, respectively. Well $3-01$ is divided into 6 layers: $2.98 \mathrm{~m}, 15 \mathrm{~m}, 37.5 \mathrm{~m}, 54.5 \mathrm{~m}$, and $66.3 \mathrm{~m}$. The conductivity values for the model layers were chosen in order to be representative of the conductivity observed in the wells and were used to produce a starting block diagram. Figure 17 shows the layered models overlain on the original induction log data, represented by the red line. 


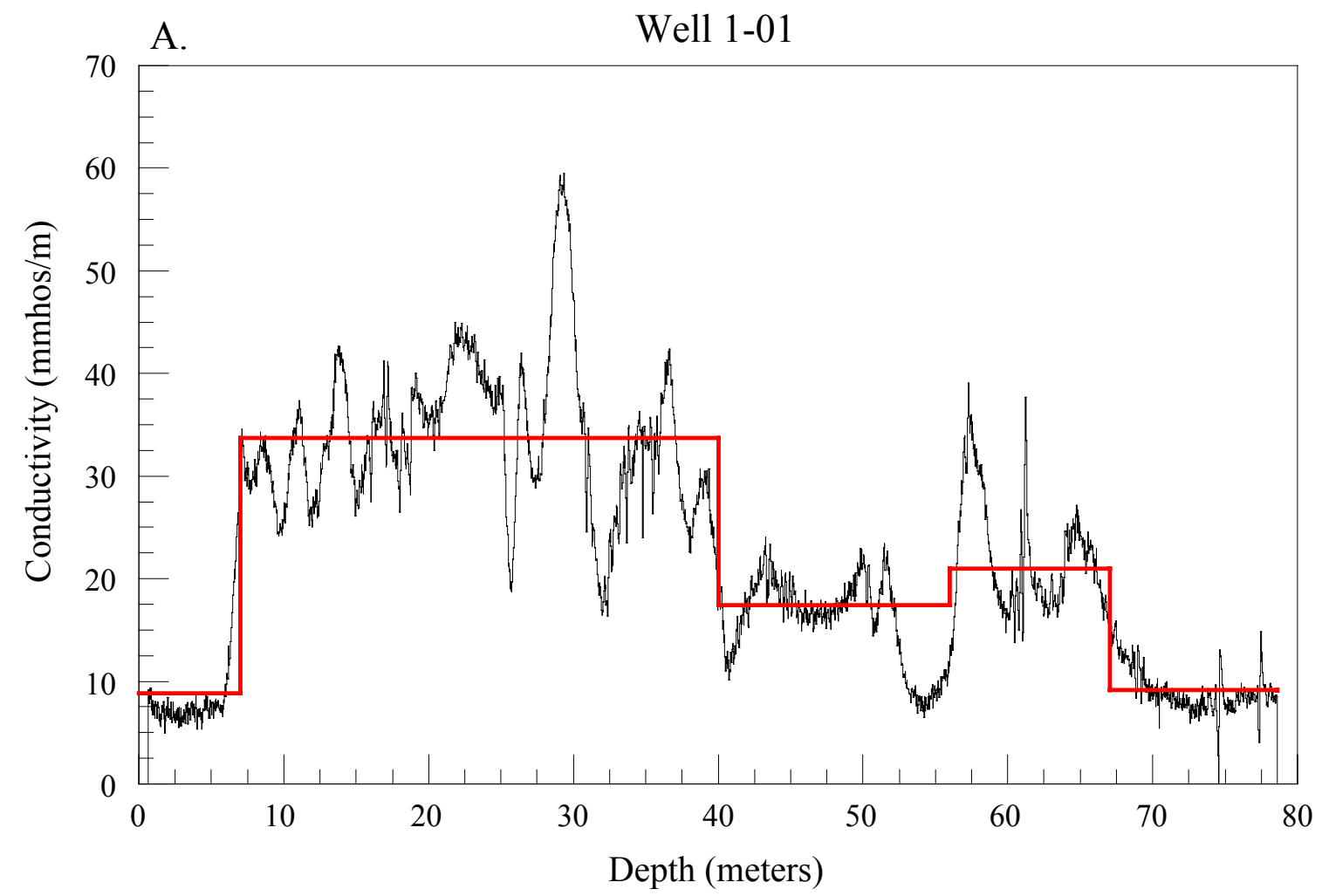

B. Well 2-01

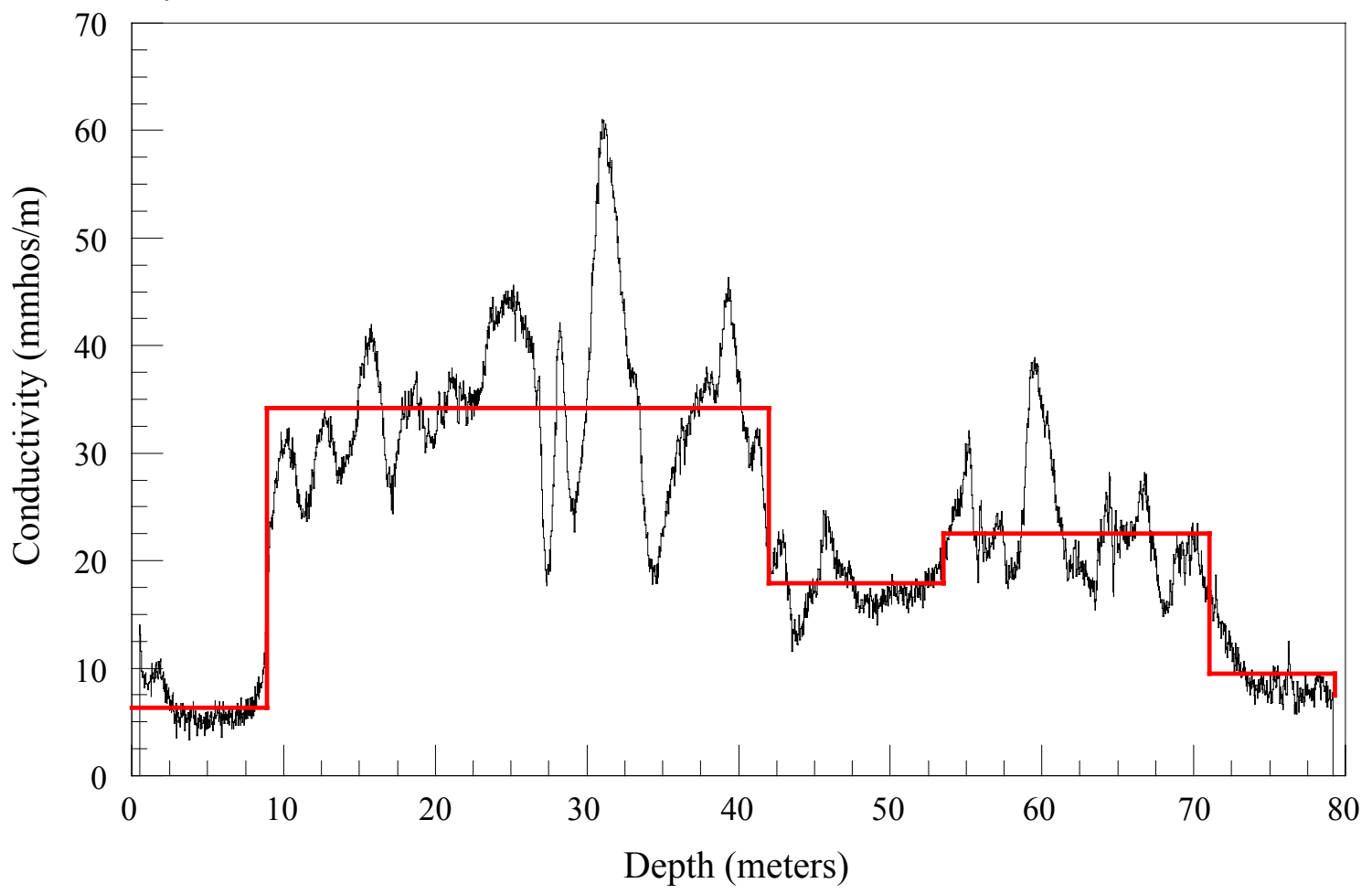




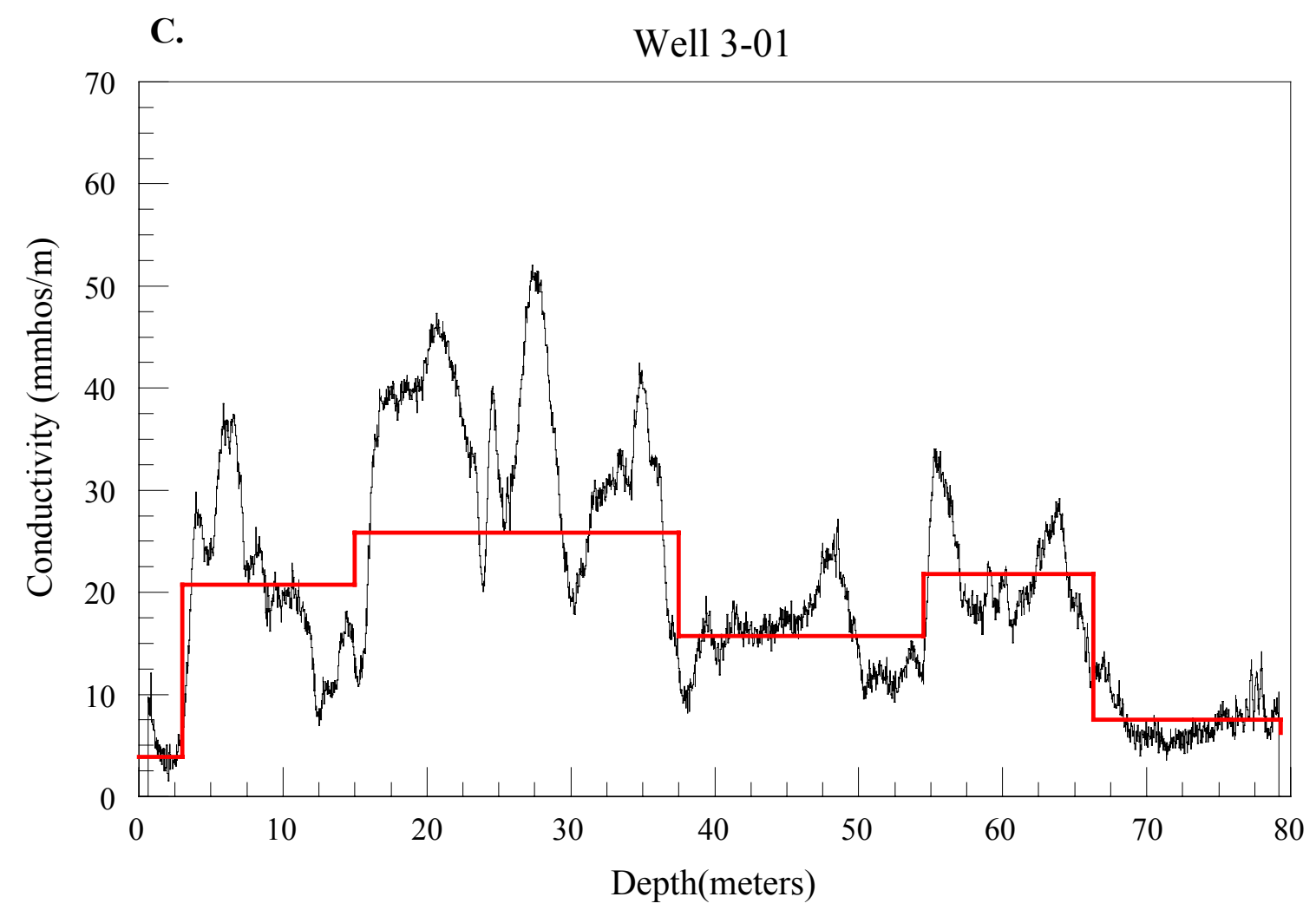

Figure 17 A, B, C: The geoelectric model layers for each well. The layered models were derived from the cumulative conductance and are indicated with the heavy red line.

\subsection{Terrain Conductivity}

Terrain conductivity soundings were conducted at wells 1-01, 2-01, and 3-01 using the $10 \mathrm{~m}, 20 \mathrm{~m}$, and $40 \mathrm{~m}$ coil separation of the Geonics EM-34 XL terrain conductivity meter. Data was collected using both horizontal and vertical dipole measurements. The borehole induction logs were divided into geoelectric layers and were used to define a starting model which, in turn, was used to predict the terrain conductivity responses (Figure 18). Using Interpex's EMIX-34 Plus modeling software, inverse models were created using the Inmanstyle ridge regression approach of nonlinear least squares curve fitting (Interpex Limited, 1989). 
Figure 18 is a graphical representation of the field observations and calculated conductivities from the starting model for three intercoil spacings. These three-point soundings consist of measurements made at the 10, 20, and 40 meter intercoil spacings. For each sounding, the calculated and observed data show similar increasing values at the $10 \mathrm{~m}$ and $20 \mathrm{~m}$ coil separation; however, at the $40 \mathrm{~m}$ intercoil spacing, the match between the observed and calculated data drops off significantly. Models were generated in order to investigate possible ways in which these differences could be explained and to minimize the great disparity between the calculated and observed data.

The simplified induction logs (Figure 17) served as starting models for the forward and inverse modeling process. In the modeling effort, the thickness of layers observed in the borehole remained fixed during the inversion; only layer conductivity was allowed to vary, meaning that the values of layer conductivity parameters could be varied during the inversion process to minimize differences between the calculated response and field observations. Inverse models are shown in Figure 19 A-C. Notice that the general conductivities derived by modeling are similar to the conductivities portrayed in the initial starting models. However, the layer conductivities derived by inversion are lower than those observed in the wells logs. The calculated and observed conductivities for the inverse model are shown in Figure 20. The anomalously low apparent conductivity observed at the 40meter coil separation suggests the presence of a real difference between the conductivity in the immediate vicinity of the borehole and the associated larger volume of surrounding strata which define the surface measurements. One reason could be lateral variations in the strata. The differences could also be attributed to the dewatering of strata overlying the mine pool 
as a result of fractures propagating upwards through the overlying rock from the mine void, resulting in anomalously low conductivity in the strata immediately above the mine void.

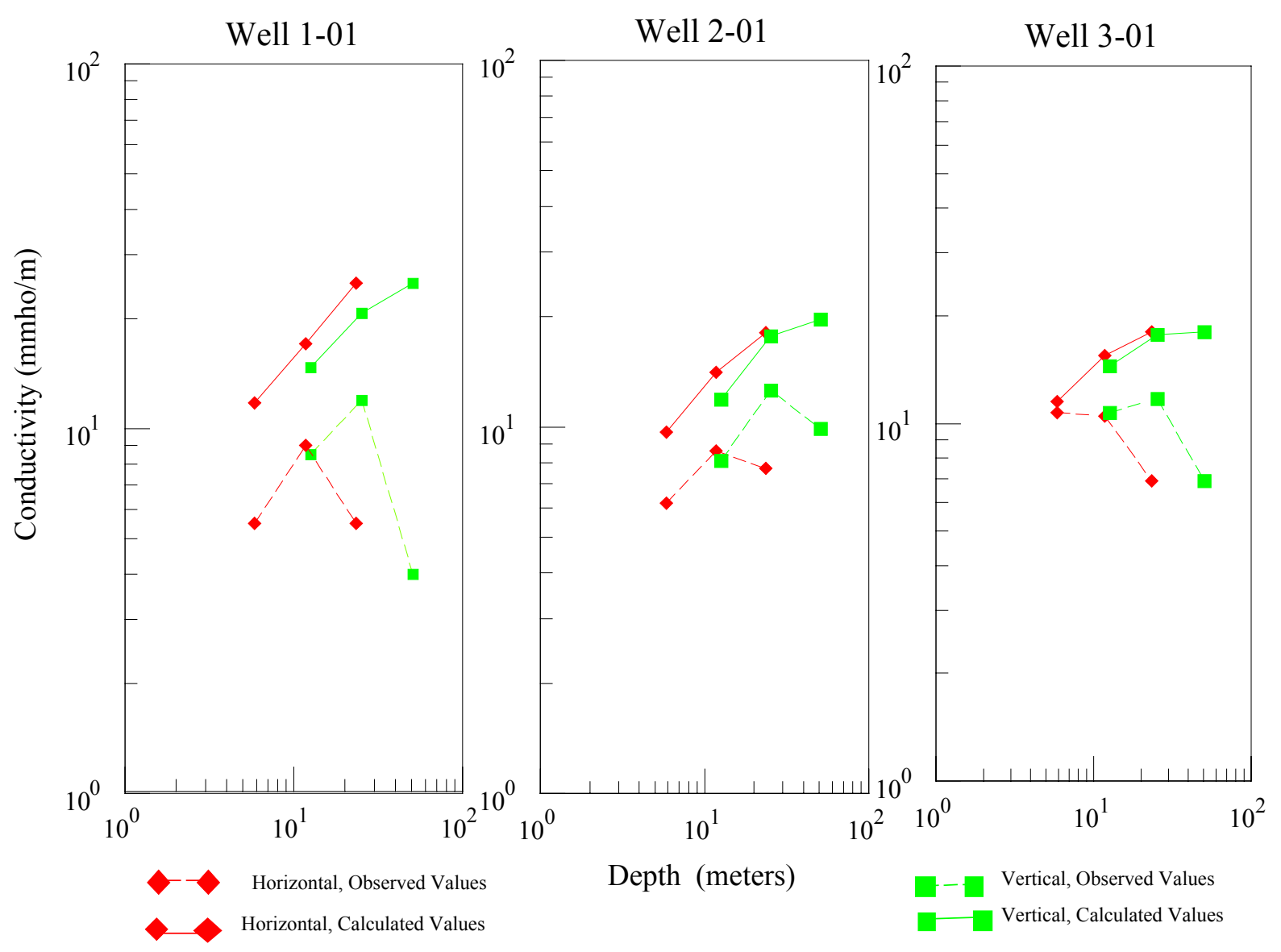

Figure 18: The observed and calculated conductivities at each well. 


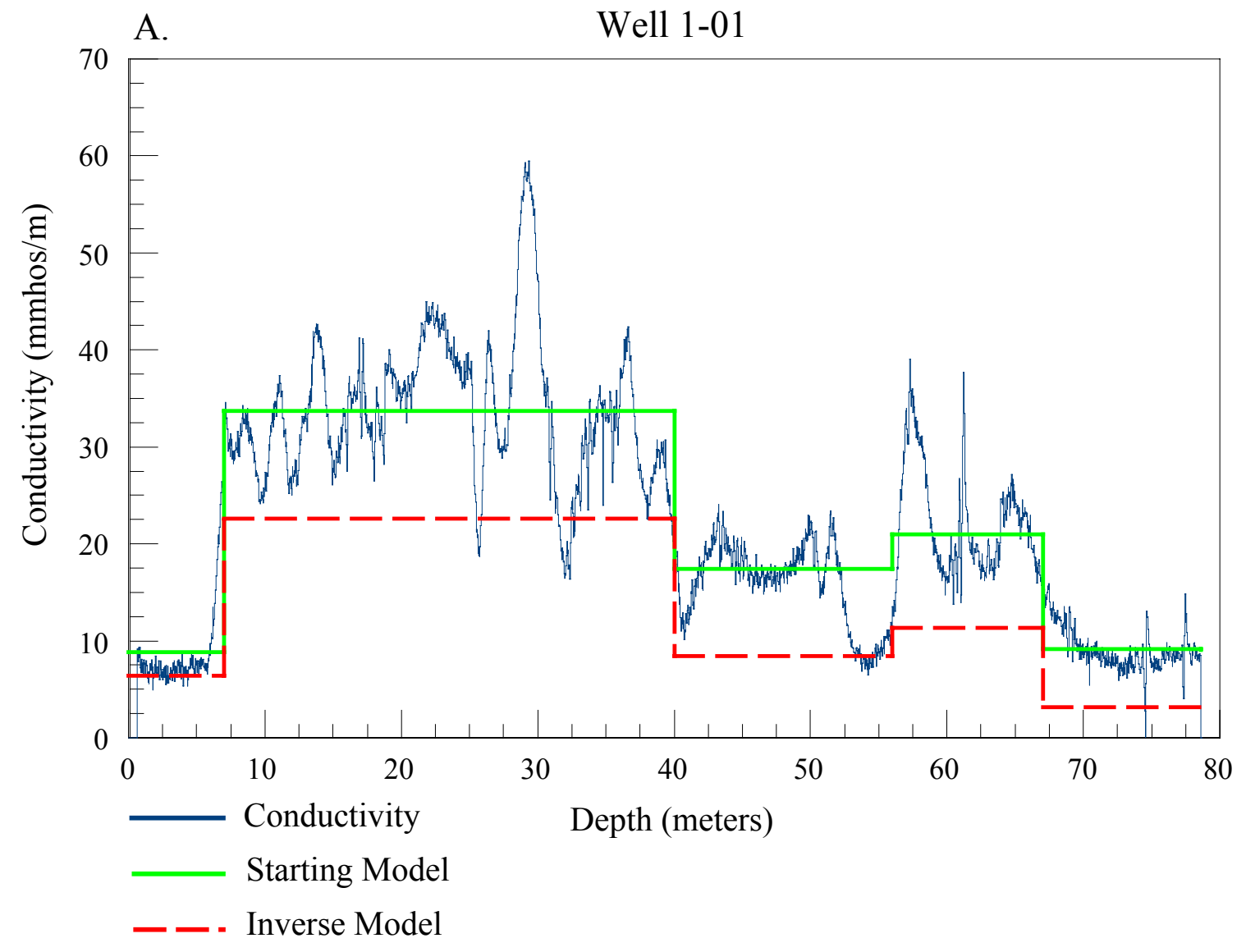


B.

Well 2-01

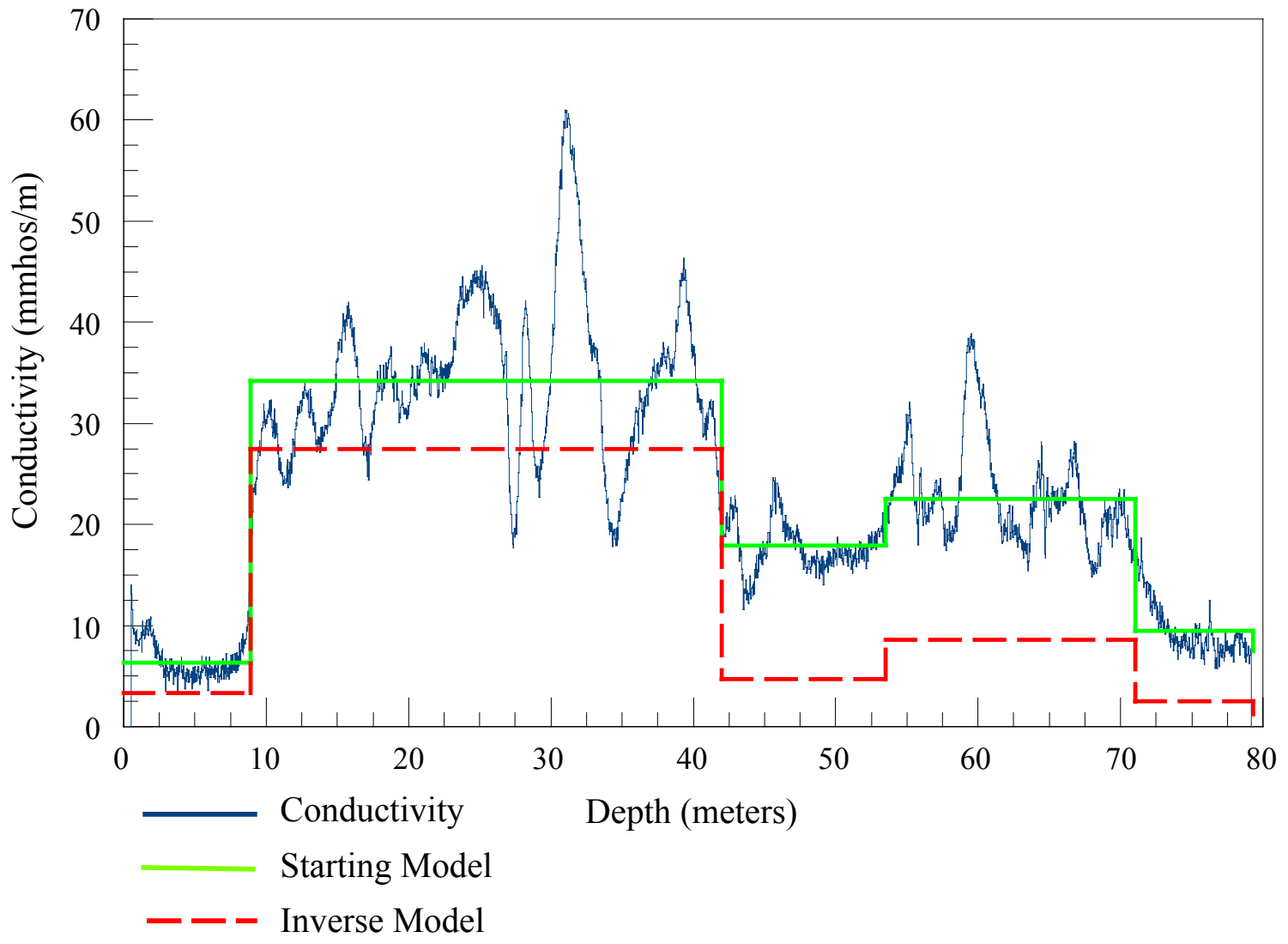




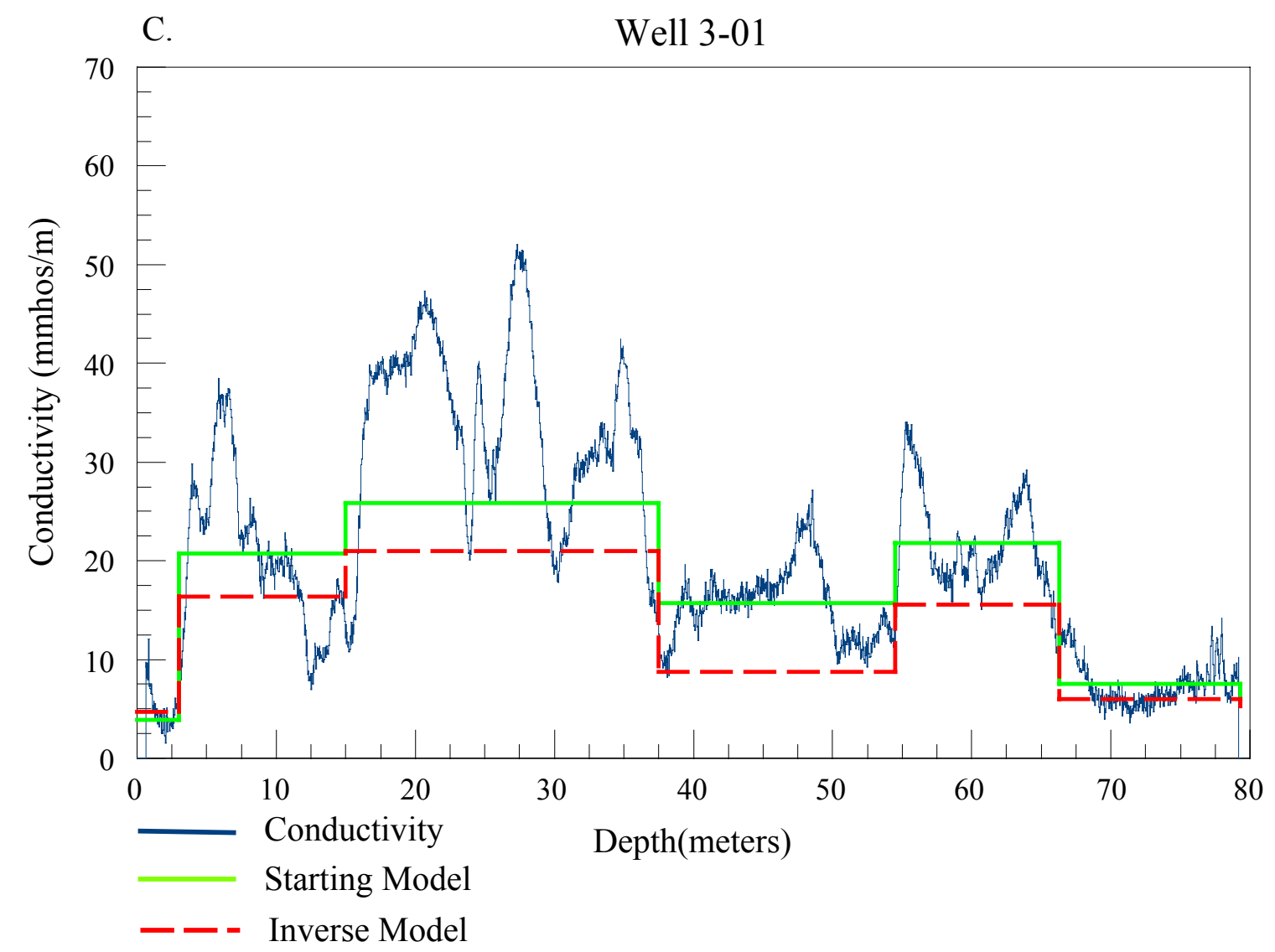

Figure 19. A, B, C: Conductivity log, starting model, and inverse model. Note that the shape of the inverse curve is similar to the starting curve, but the conductivity is less suggesting a real difference in surrounding strata. The \%RMS for each inversion is $30 \%, 18 \%$, and $24 \%$, respectively. 

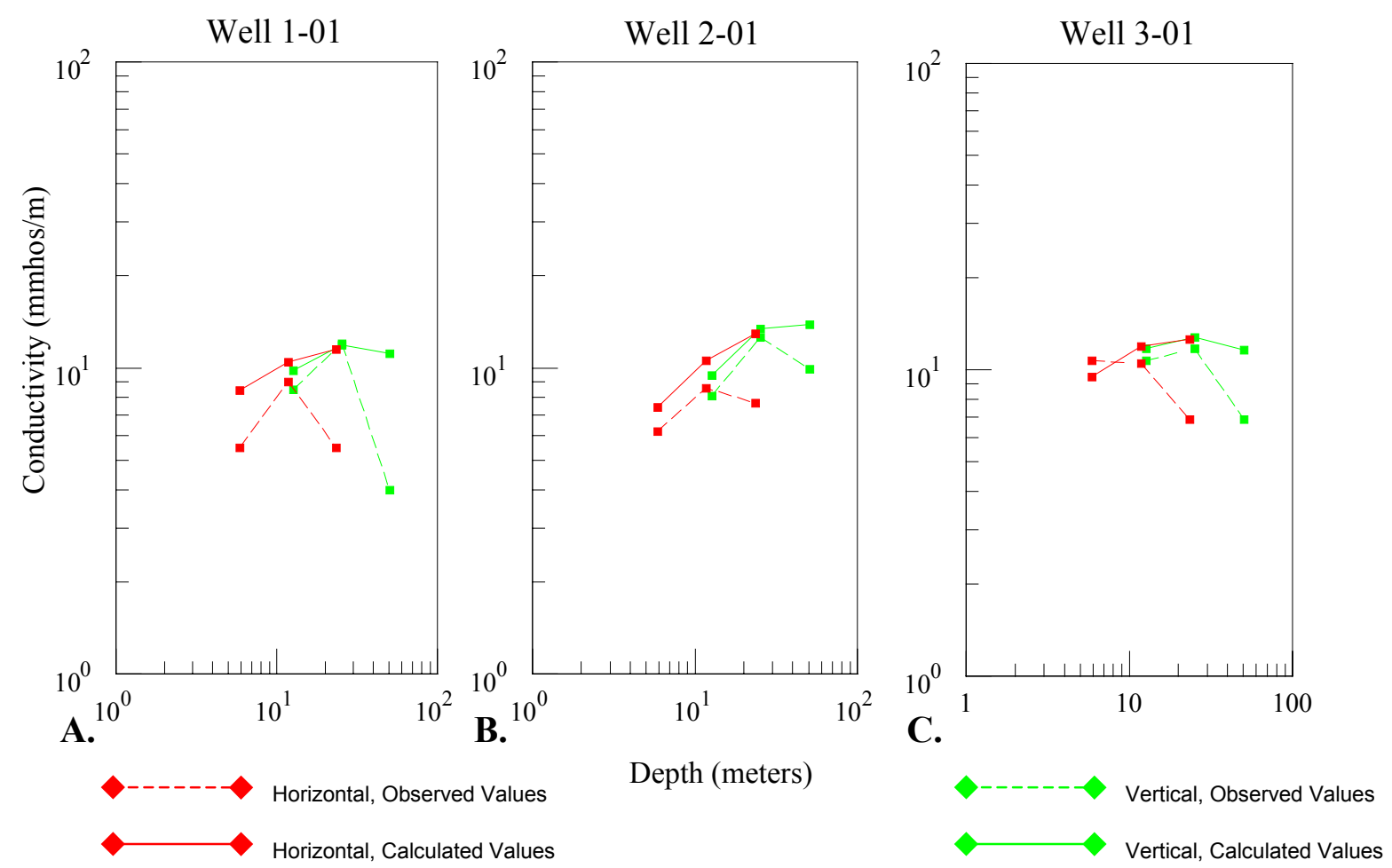

Figure 20 A, B, C: The calculated and observed conductivity values at each well after the inversion process. Note that the great disparity between the two values at the 40-m separation value, which may be indicative of variations in local strata.

The mine void was added as a high-conductivity layer to the input model and an inverse model was generated. The calculated conductivities were then used as an input model with the mine void as an air-filled layer with no conductivity. The purpose of this exercise was to determine if there was a resolvable difference between a low conductivity air-filled void and a highly conductive mine pool. A comparison of the calculated and observed conductivities between an air-filled void and AMD-filled mine workings is shown in Figure 21. The RMS difference is $2.09 \%$. With such a small difference between the two situations, one can conclude that it would be impossible to differentiate between AMD or air-filled mine workings using terrain conductivity soundings. The difference is significantly smaller than the error observed in the foregoing comparison between the inverse model 
calculations and observations. The chances that such a small difference could be uniquely associated with the presence or absence of mine contamination is miniscule.

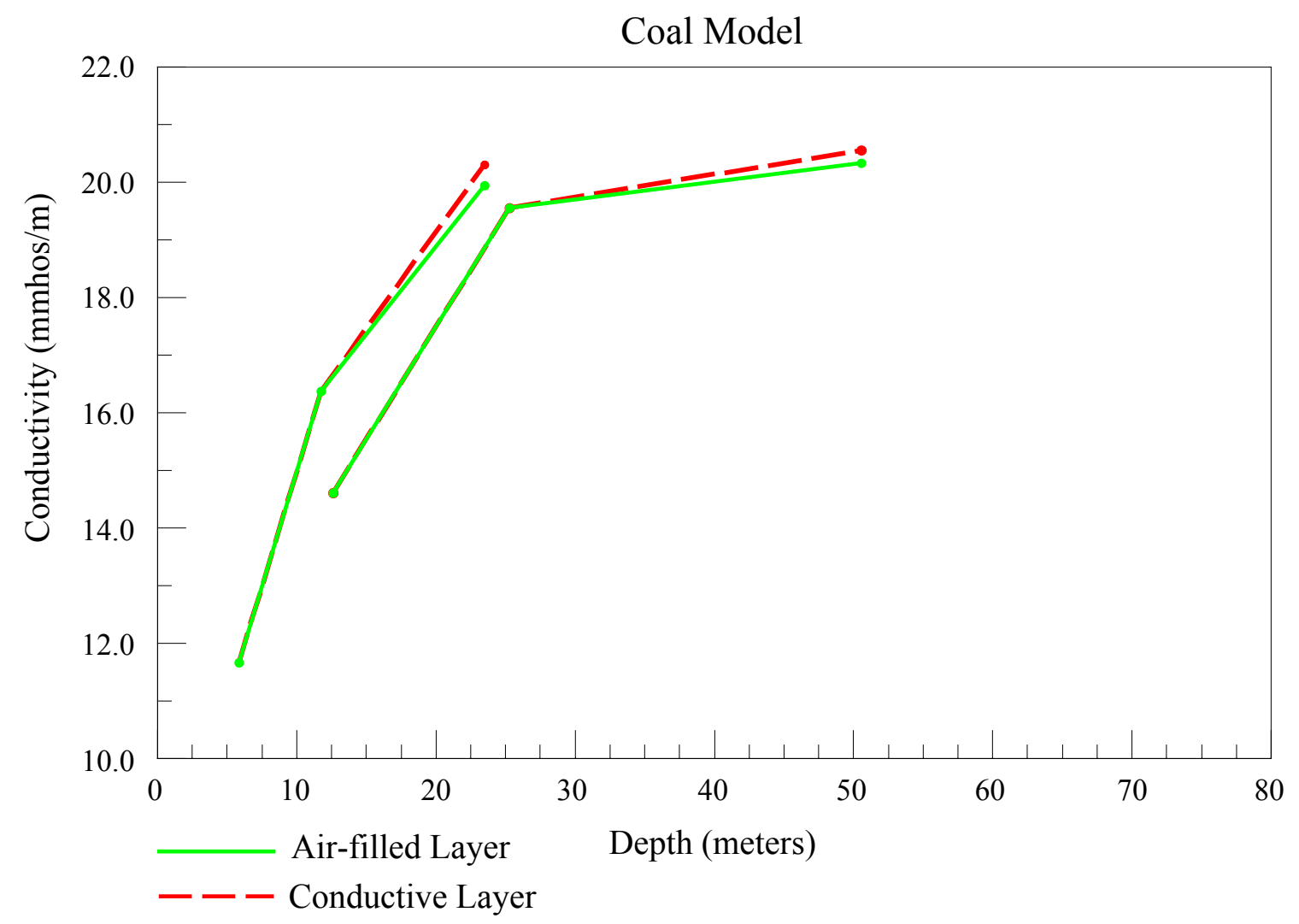

Figure 21: The calculated difference between the mine void as an air-filled layer and as a conductive layer. The percent difference is $2.09 \%$.

\subsection{Resistivity}

Field studies also included acquisition of resistivity soundings in areas adjacent to Wells 1-01 and 2-01. Dipole-dipole and Wenner soundings were surveyed using AGI's resistivity meter, Super Sting R8/IP. In the Super Sting, survey all electrodes are set out initially along the profile lines. For this survey, a total of 56 electrodes were driven into the ground at 4 meter intervals along the profile. Resistivity measurements are controlled by internal software. The algorithm selects combinations of current and potential electrodes along the length of the electrode array. The measurement process takes about 45 minutes for 
the dipole-dipole survey and 2 hours for the Wenner survey. Data from the resistivity soundings are then imported into Microsoft's Excel to extract individual soundings. The soundings were imported into RES2DINV (www.geoelectrical.com), a program which generates a 2-D inverse resistivity model using a smoothness-constrained least-squared method. The model is displayed as a psuedosection. Figures 22 and 23 depict the 2-D inverse models calculated for the dipole-dipole and Wenner surveys. Note in both images the highly resistive unit at the top of the section. This unit corresponds to the Grafton Sandstone, a resistive sand, which crops out in the survey area. The resistivity in the model decreases with depth.

Soundings were extracted from the Wenner array profile data and modeled using Interpex's IX1D (www.interpex.com). Figure 24 depicts the results obtained from the inverse modeling of one sounding along the profile. The inverse models obtained by IX1D are very similar to those shown in the psuedosections (Figures 22 and 23). The model reveals a highly resistive unit near the surface that extends from about 0.3 meters to 4 meters beneath the surface. The interval correlates to the Grafton Sandstone (first sandstone interval, Figure 2) mentioned above and may also include some of the underlying strata. In order to match the observed and calculated data, a highly thick, highly resistive unit near the top of the section must be present, and as observed in the 2-D inversion, the resistivity decreases with depth. 


\section{T\&T Mine Site \\ Dipole-Dipole Array \\ 4-m Electrode Spacing}
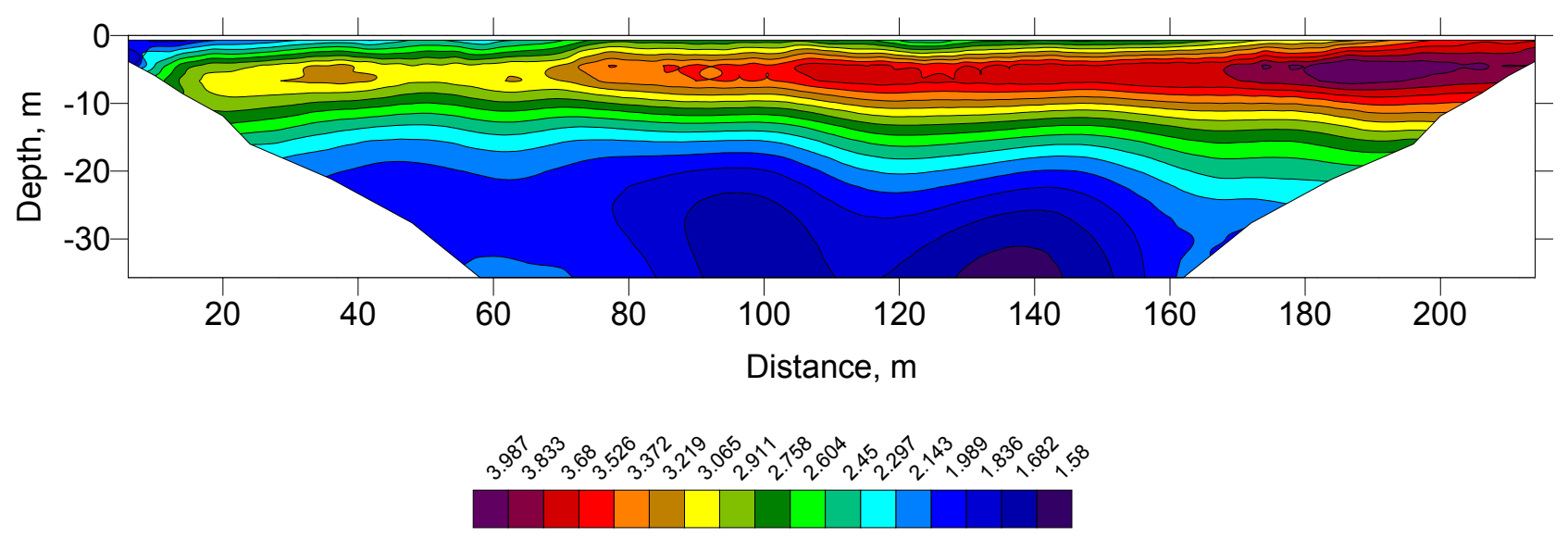

\section{Log Resistivity, ohm-m \\ T\&T Mine Site \\ Wenner Array \\ 4-m Electrode Spacing}

Figure 22: The inverse model for the dipole-dipole array displayed as a psuedosection. Note the highly resistive layer at the top.
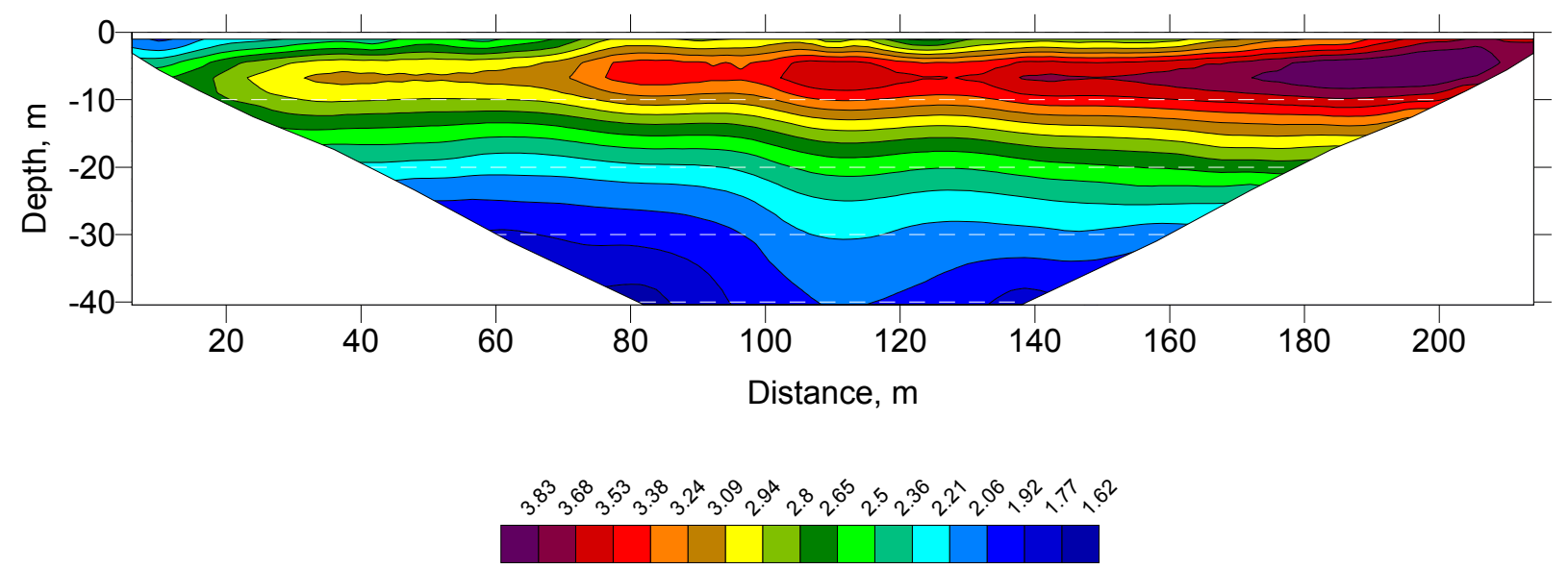

Log Resistivity, ohm-m

Figure 23: The inverse model of the Wenner array survey displayed as a psuedosection. Note the high resistivity layer near the top of the section. 


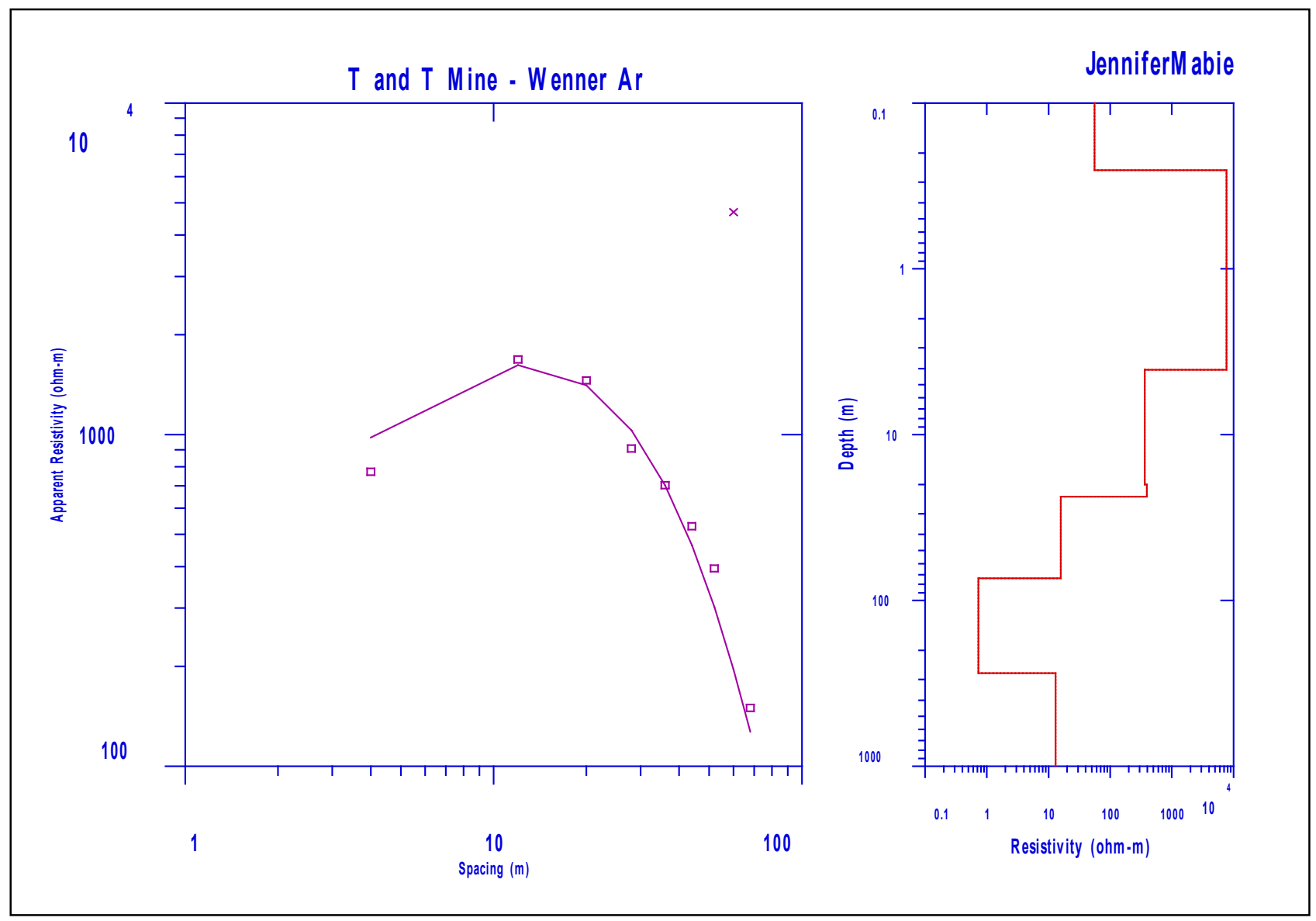

Figure 24: The graph on the left is the observed and calculated resistivity data from the sounding performed in areas adjacent to Wells 1-01 and 2-01. Note the high data point has been masked and not included in the calculations. The graph on the right is layered inversion of the resistivity data. The high resistivity interval correlated with the Grafton Sandstone. The RMS difference between the calculated and observed resistivity data is $16.77 \%$.

The results of resistivity modeling indicate that the highly resistive layer near the top of the section serves as a barrier to current flow into the deeper section. A high resistivity interval (low conductivity) also appears in each of the terrain conductivity models. However, in the case of terrain conductivity surveys, the propagation of transmitted electromagnetic waves is not impeded by the presence of a low conductivity interval. 
Problems in resistivity surveys can arise when highly resistive units are present in the subsurface. The resistivity response at target depths cannot be measured in when overlying highly resistive zones inhibit current flow to the target interval (Merkel, 1972). The high resistive near surface layer observed in this study prevents measurements of meaningful apparent resistivity from depths below approximately 10 meters. Layers in the models appearing below a depth of a few meters appear to have a lower resistivity and are most likely due to limited current flow through deeper intervals.

\subsection{Time Domain Electromagnetic Methods}

Two time domain electromagnetic (TDEM) surveys were completed in areas adjacent to Wells 1-01, 2-01, and 3-01. Due to improper instrument configuration and possible instrument failure, no useful data was collected. Another survey with proper instrument configuration would be useful as TDEM soundings are able to resolve conductors at depths greater than those obtained with terrain conductivity soundings. Other methods, such as controlled-source audio frequency magneto-telluric (CSAMT), which have been used for

groundwater exploration and monitoring, are being investigated by the US Department of Energy in order to determine if such technology is applicable in an environmental application. 


\section{Chapter 4 - Airborne Analysis Results and Discussion}

\subsection{Airborne Electromagnetic Conductivity}

Five frequencies of airborne electromagnetic data were collected over the T\&T Mine Complex as part of the Muddy Creek/Roaring Creek Watershed airborne survey. The data were collected using Fugro's DIGHEM ${ }^{\text {VRES }}$ electromagnetic data acquisition system. The frequencies ranged from $390 \mathrm{~Hz}$ to $102,680 \mathrm{~Hz}$. The flight lines over the T\&T mine site were extracted and imported into EM Flow, an airborne electromagnetic (EM) modeling program (Macnae, 2001).

EM Flow, developed by CRCAMET, an Australian minerals exploration research organization, uses theoretically defined EM system waveforms to deconvolve measured EM multi-component, multi-channel line data. The software is designed to operate on large EM datasets such as the T\&T data set and provide conductivity-depth images (CDI), plus anomaly identification and modeling tools (Macnae, 2001).

Conversion of observed EM data to time constant (Tau) domain is achieved by deconvolving the input data with a pre-computed ideal waveform (Macnae, 2001). A typical modeling operation involves analysis of one or a select group of traverse lines and their acquired EM data. The appropriate Tau analysis range is defined, the controlling parameters are selected, and then the deconvolution and the CDI creation process can be applied to the selected dataset and allowed to operate in a batch style of operation (Macnae, 2001). Topography is taken into account for depth solutions and will form the upper surface of the CDI's. All flight lines for the T\&T Mine Complex were processed, but for the purpose of this study, only the flight lines that corresponded with well location are considered. 
Figures 25, 26, and 27 are conductivity-depth images (CDI) for flight lines 10780, 1790 , and 10850, which are in close proximity to wells 1-01, 2-01, and 3-01 from the T\&T Mine Complex. A digital orthophoto quarter quadrangle (DOQQ) is coupled with each CDI in order to indicate the flight line location, shown by a heavy red line, in relation to the wells. Portions of these flight lines overlie approximately 90-m deep, partially flooded, mine workings indicated in orange on Figures 25-27. The water in the flooded mine is known to be conductive ( $>500 \mathrm{mS} / \mathrm{m})$. The elevation (in meters) is indicated on the side of the CDI and represents topography. Information included on each CDI are the corresponding flooded mine areas (orange shading), the power line locations (vertical red lines), and well locations (vertical orange lines).

Figure 25 is the CDI and DOQQ for flight line 10780. The feature marked "A" represents an unknown anomaly of high conductivity. The depth of this conductive area is about 160 meters below the surface - too deep in the section to be considered for the flooded mine. The feature marked "B" is an anomaly associated with the power line. The deep anomaly in the vicinity of the power line is the result of interference. The area marked "C" is a topographic low. In this area, the bird height greatly exceeded the optimum bird height of 30 meters, resulting in a signal dropout. No useful data can be obtained from this low area. Additionally, the flying height of the bird exceeded 30 meters at the end of each flight line, making data obtained at flight line ends of no value. There are several deep, conductive features that were identified below the exploration depth for the frequencies used and also below the depth of the mine pool. These conductors are believed to be artifacts of data processing and have no geological relevance. The feature marked " $\mathrm{D}$ " is a near-surface conductor (appears as a thin, yellow band) that could represent the water table; it is more 
conductive in areas that underlie surface mines. This layer is too shallow in the section to represent the underground mine. Because the thin conductor follows topography, it could also be an artifact of processing. There are no significant anomalies in areas adjacent to Well 2-01.

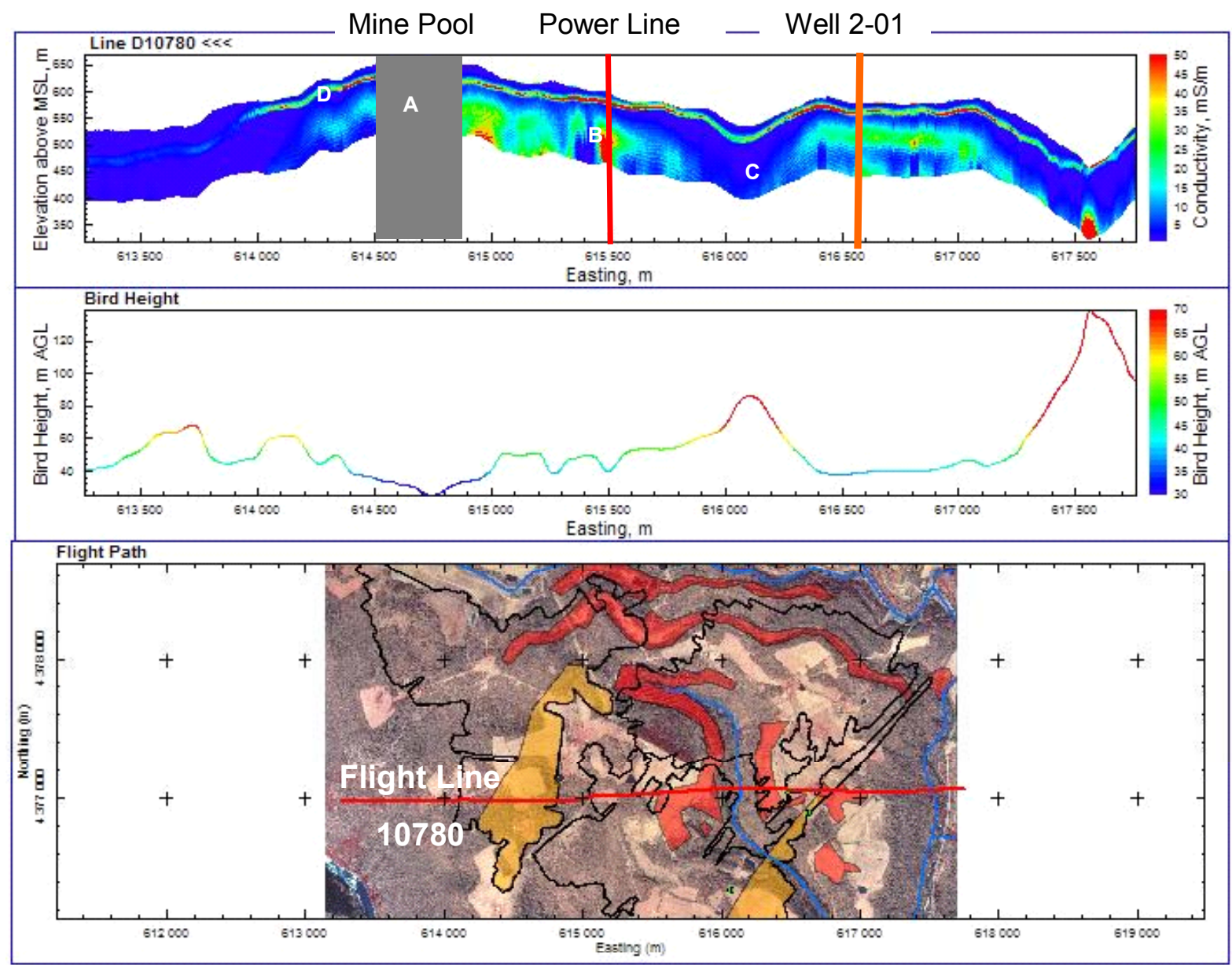

Figure 25: The CDI for flight line 10780. Feature A is an anomoly in the mine pool area, but is below the depth of the mine pool and is thought to be an artifact of data processing and have no geologic relevance. Area $\mathrm{B}$ is a conductor in the vicinity of the power line is a result of power line interference. Area $\mathrm{C}$ is a result of signal dropout as the bird exceeded the optimum height of 30 meters. The near- surface conductor is believed to represent the water table in the area.

Figure 26 is the CDI, bird height graph, and DOQQ for flight line 10790. There are no anomalous features that may be associated with the flooded underground mine. The feature marked " $\mathrm{A}$ " is a conductive high associated with the power line. The area marked 
"B" represents the signal dropout. Generally, the blue areas in the CDI beneath valleys indicate that the sensor was too high to obtain adequate response from low frequencies. The anomaly at depth in the areas adjacent to " $\mathrm{B}$ " is interpreted as an artifact resulting from the combination of noisy data and the inversion processes of EM Flow. Other deep anomalies are conductors that are too deep to be the associated with the mine, and are assumed to be processing artifacts. The conductive layer relatively close to the surface "C" is thought to be representative on the regional water table, though it also could be an artifact of processing. There are no anomalous features in the vicinity of Well 1-01.

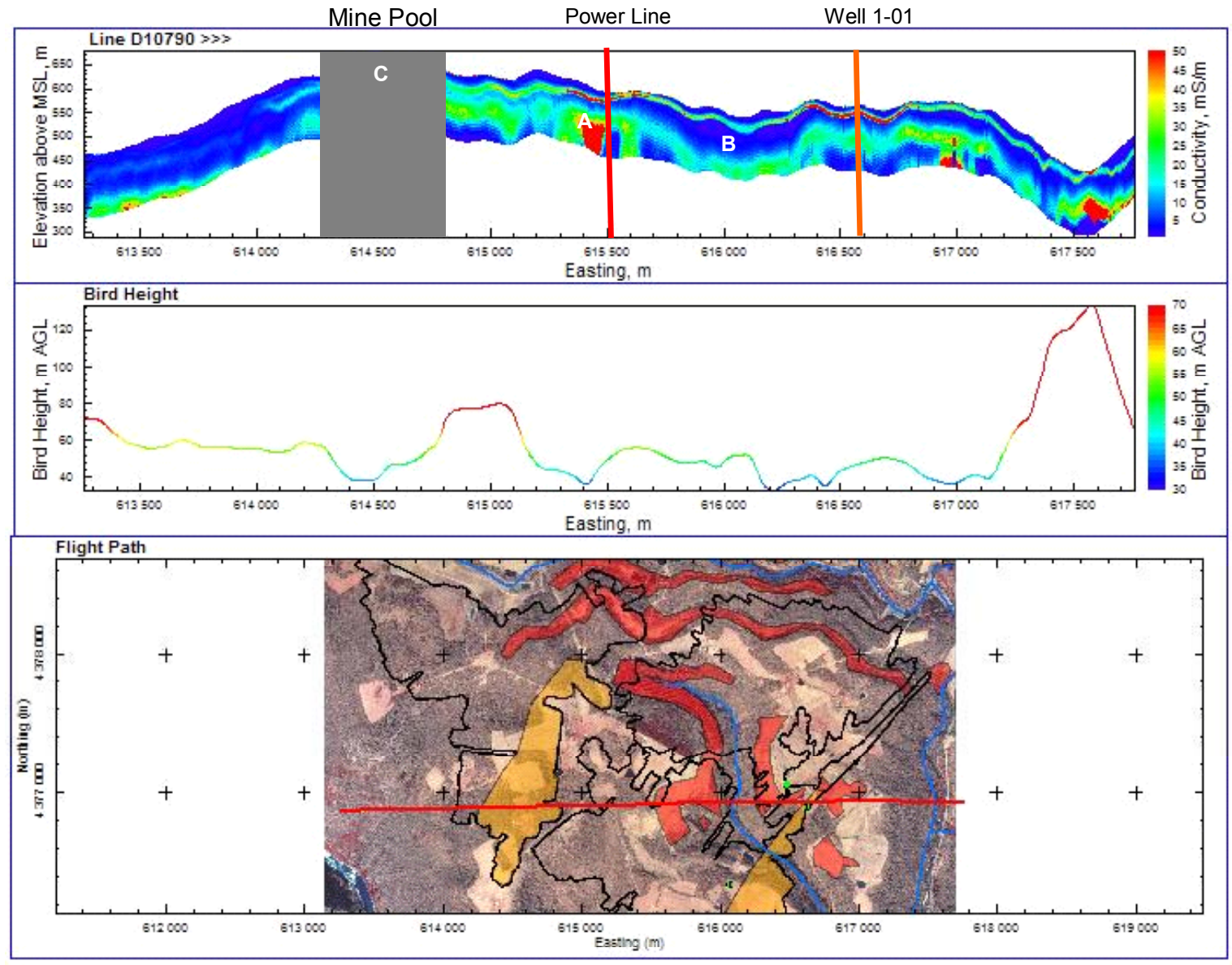

Figure 26: The CDI for flight line 10790. There are no significant anomalies associated with the mine pool, indicated by the orange shading. " $\mathrm{A}$ " indicated the powerline signature from processing the data. " $\mathrm{B}$ " indicates a topographic low in which the sensor was too high to obtain adequate response from low frequencies. " $\mathrm{C}$ " indicates a thin, near-surface conductor which may represent the regional water table. There are several deep conductors which are thought to be processing artifacts. 
Figure 27 is the CDI, bird height graph, and DOQQ of flight line 10850. The sensor height during the acquisition of flight line 10850 was excessive and resulted in broad areas where the CDI process could not achieve an adequate solution (blue areas). The high conductivity feature marked " $\mathrm{A}$ " is a result of the power line. The area marked " $\mathrm{B}$ " is an anomaly that may be an artifact from the deconvolution process. The area marked $\mathrm{C}$ is a thin, continuous conductor that could be interpreted as the regional water table, or as processing artifacts. There are no significant anomalies in the flooded portion of the mine. The anomalous regions present are too deep in the subsurface to be associated with underground mine and anticipated mine pool.

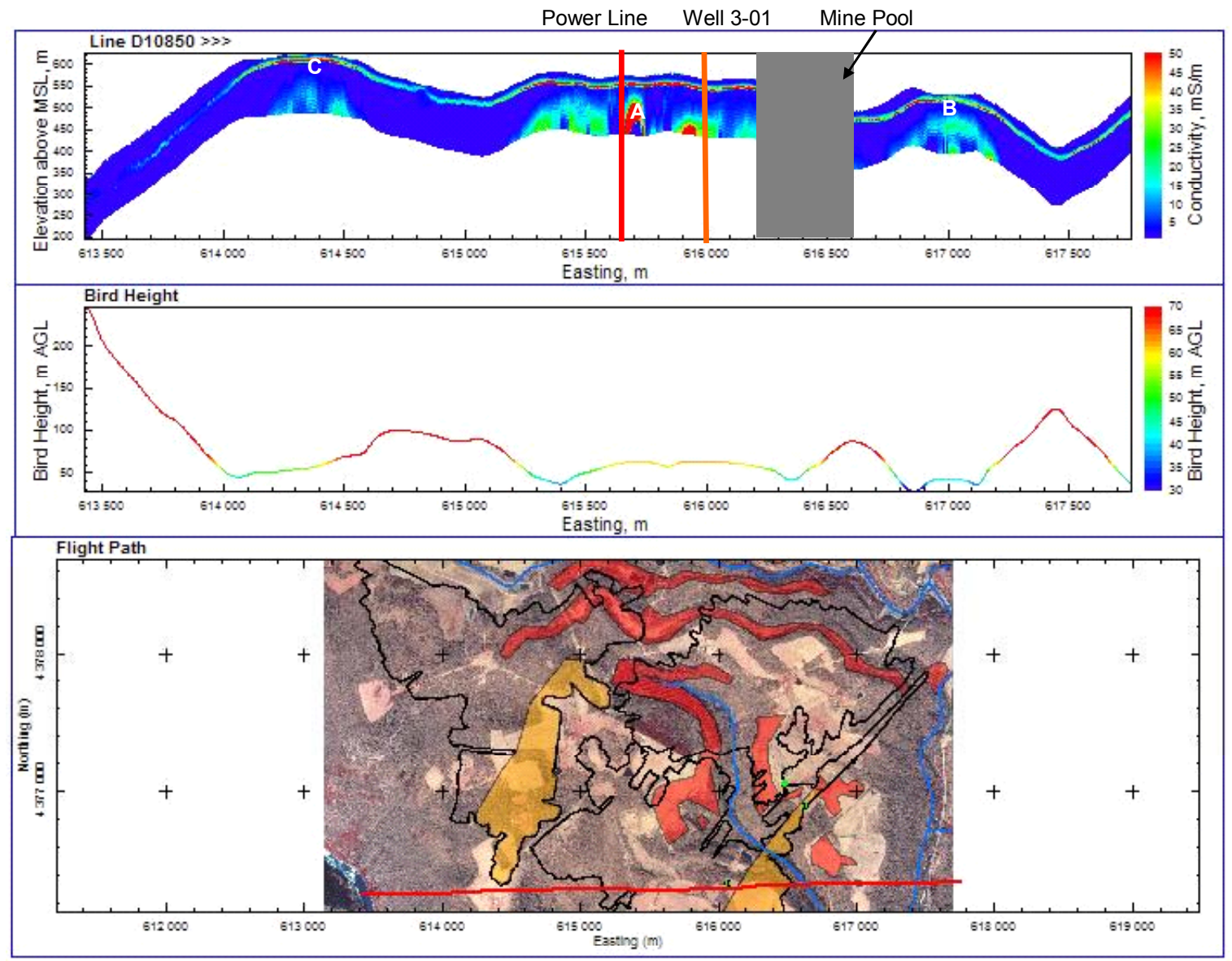

Figure 27: The sensor height during the acquisition of flight line 10850 was excessive and resulted in broad areas where the CDI process could not achieve an adequate solution (blue areas). However, the near-surface conductor is present in most of the CDI profile. 
No CDI indicated a conductive anomaly at the depth and location of the mine pool. The average depth to the mine pool is about $90 \mathrm{~m}$ along the flight lines, which is near the calculated exploration depth for the $390-\mathrm{Hz}$ frequency. However, the $390 \mathrm{~Hz}$ data could not be used in the construction of CDI profiles because of excessive noise. Some of the noise can be attributed to the high-voltage power line that extends across the site perpendicular to flight lines, and was therefore unavoidable. Additional noise occurred as a result of excessive sensor height and the swinging of the bird, which can be attributed to an inexperienced pilot.

Figure 28 is a generalized model generated by Furgo (2001). Figure $28 \mathrm{~A}$ is a simple model section with the mine pool having a conductivity of $500 \mathrm{mS} / \mathrm{m}$ and a thickness of 2-3 meters and an average overburden conductivity of $20 \mathrm{mS} / \mathrm{m}$ (Fugro, 2001). Figure $28 \mathrm{~B}$ is the forward model results. Figure $28 \mathrm{C}$ is the inverse model results. The model results indicate that one would possibly be able to resolve a mine pool at the approximate depth of 50 meters, under the best conditions (Fugro, 2001). At depths greater than 50 meters, the noise is greatly increased resulting in questionable inversion results. A conductive mine pool at a depth of 90 meters, as is the case at T\&T, would not be detected, given the model parameters. Without the $390 \mathrm{~Hz}$ data, the ability to detect a conductive mine pool at depth is greatly reduced. 

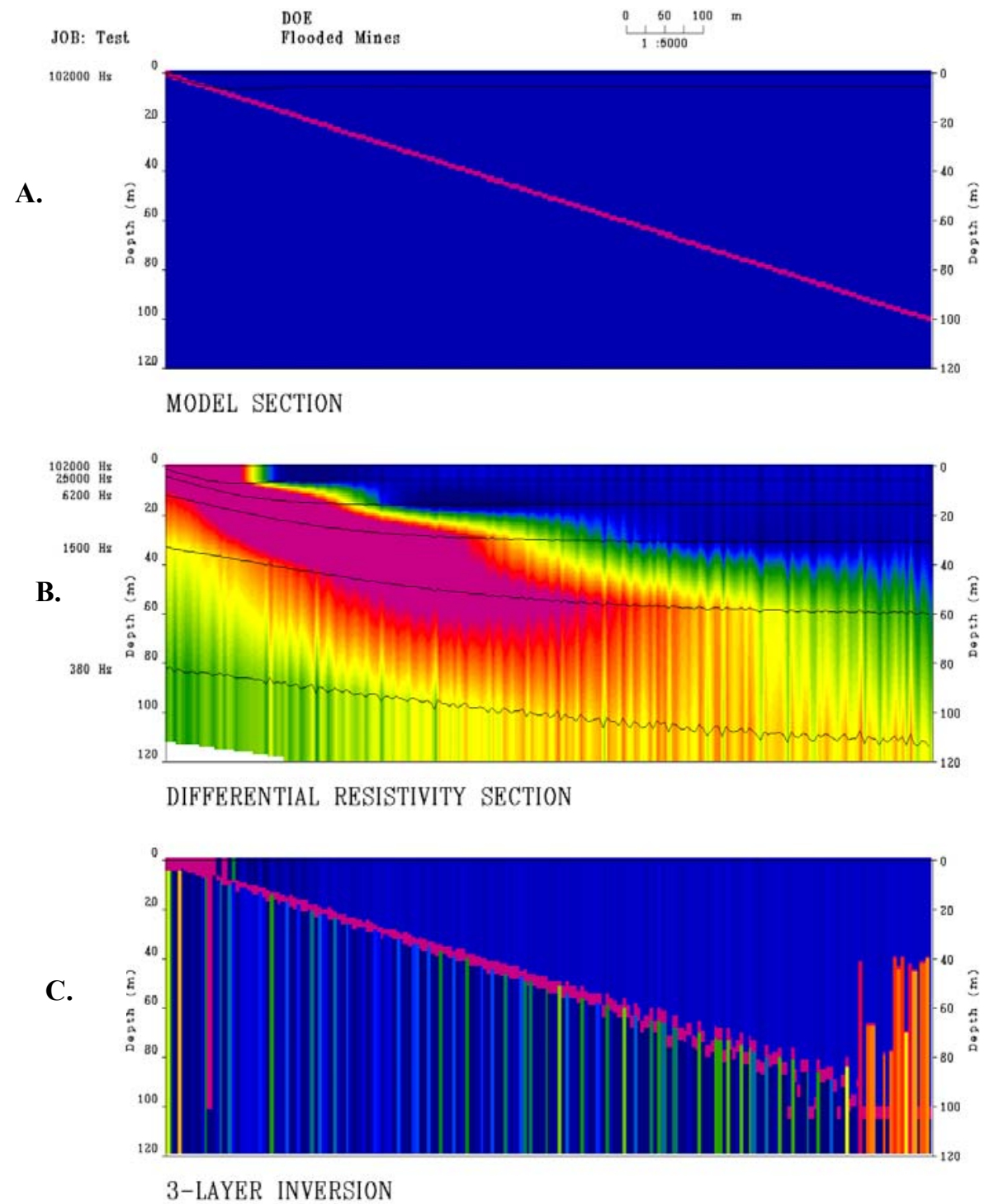

Figure 28 A, B, C: Forward model constructed using a 2-m thick mine pool by Fugro (2001). Figure A is a simple model section with the mine pool having a conductivity of $500 \mathrm{mS} / \mathrm{m}$ and an average overburden conductivity of $20 \mathrm{mS} / \mathrm{m}$ (Fugro, 2001). Figure B is the forward model result. Figure C is the inverse model result. 
Figure 29, 30, 31 are a comparison of the CDI's of flight lines 10780, 10790, and 10850 with the down-hole conductivity log and inversion EM-34 data. The depth interval for each graph is 80 meters. The CDI is cropped to include only areas immediately adjacent to well locations. The actual well location is denoted with the heavy, dashed line. As discussed previously, the forward model of the airborne survey data suggests that detection of conductors to a depth of 50 meters under the best survey conditions using all 5 frequencies is possible (Fugro, 2001). At this survey location, with sub-optimal survey conditions, the airborne survey results reveal subsurface information up to an approximate depth of 40 meters. The graphs portray details of the vertical distribution of conductivity up to depths of approximately $40 \mathrm{~m}$. However after 40 meters, the resolution of the airborne data in comparison to the ground data is poor. The high conductivity layer in the CDI's in the figures corresponds to the thin, laterally extensive conductor near the surface noted on the CDI's in figures 25,26 , and 27 . This could represent the water table in the area. This thin conductor could also be an artifact of the deconvolving process of EM Flow. 


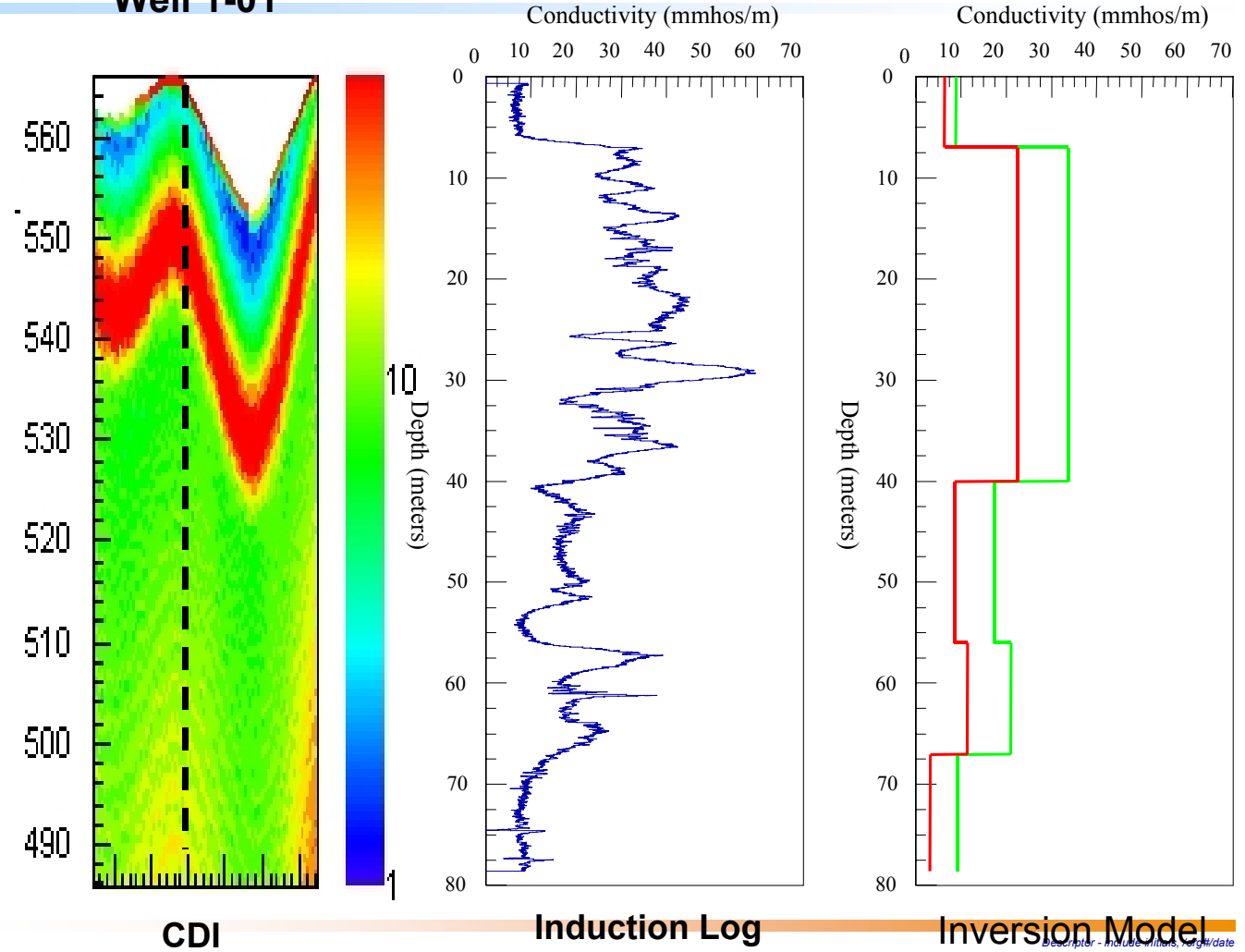

Figure 29 A, B, C: A comparison of the airborne, borehole induction log, and the inverse model for Well 1-01. The well location is denoted with a black dashed line on Figure A. The elevation is located on the left of figure A, the conductivity $(\mathrm{mS} / \mathrm{m})$ is denoted with the color bar on the right of Figure A. Figure B is the conductivity $\log$. Figure $\mathrm{C}$ is the starting model (green line) and the inverse model (red, dashed line) for the EM-34 soundings at Well 1. 


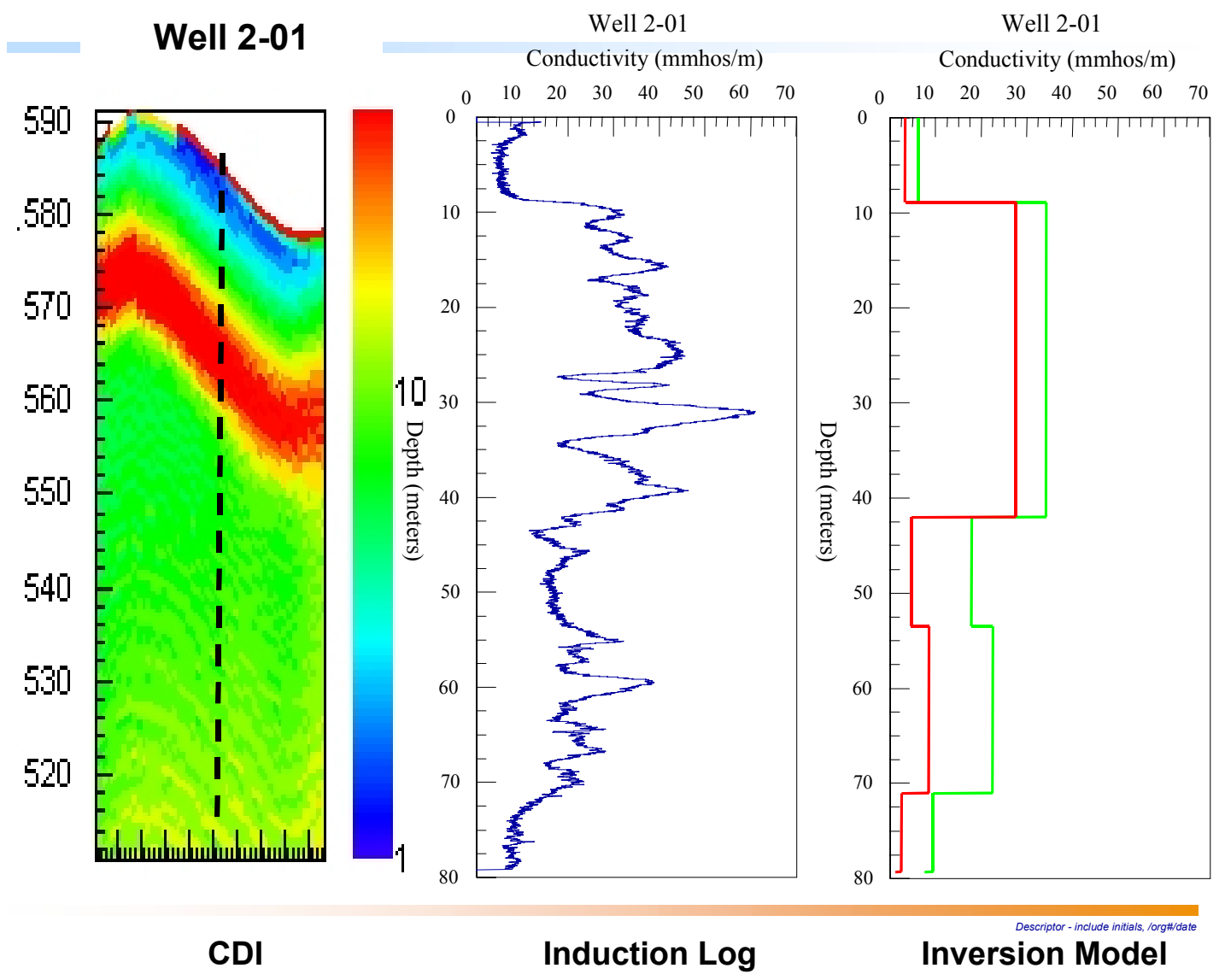

Figure $30 \mathrm{~A}, \mathrm{~B}, \mathrm{C}$ : A comparison of the airborne, borehole induction log, and the inverse model for Well 2-01. The well location is denoted with a black dashed line on Figure A. The elevation is located on the left of figure A, the conductivity $(\mathrm{mS} / \mathrm{m})$ is denoted with the color bar on the right of Figure A. Figure B is the conductivity log. Figure $\mathrm{C}$ is the starting model (green line) and the inverse model (red, dashed line) for the EM-34 soundings at Well 2. 


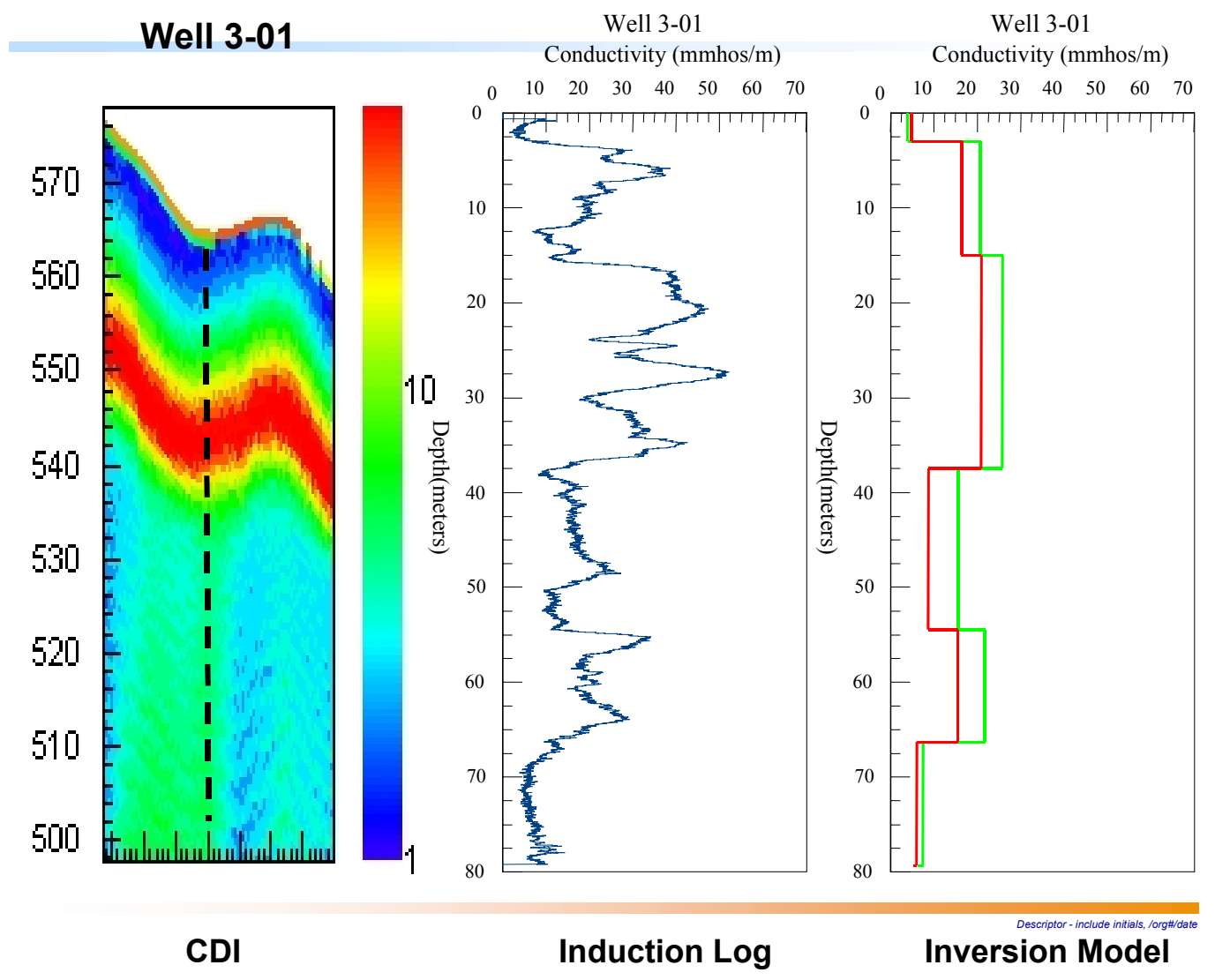

Figure 31A, B, C: A comparison of the airborne, borehole induction log, and the inverse model for Well 3-01. The well location is denoted with a black dashed line on Figure A. The elevation is located on the left of figure A, the conductivity $(\mathrm{mS} / \mathrm{m})$ is denoted with the color bar on the right of Figure A. Figure B is the conductivity log. Figure $\mathrm{C}$ is the starting model (green line) and the inverse model (red, dashed line) for the EM-34 soundings at Well 3. 


\subsection{Thermal Infrared Imagery}

Figure 32 depicts seven thermal infrared imagery lines acquired during the nighttime flight over the T\&T Mine Complex. The TIR images have been overlain on a USGS false color (DOQQ).

Image mosaicking was used to combine the individual flight lines to generate a composite image. Mosaicking is the process of joining georeferenced images together to form a larger image or set of images. The Erdas Imagine mosaicking module was used to generate the mosaic.

For full understanding of the site, as well as site characterization and analysis of data, a comprehensive geographical information systems (GIS) project was assembled. Table 2 lists the significant layers used in this project for analysis.

Typically, data processing procedures for thermal infrared imagery includes separating land features from water features, particularly ground water that comes to the surface as springs or seeps. Mine drainage should have temperature characteristics similar to local ground water flow systems. Ground water is warmer than surface water, such as streams, which are in turn warmer than land during November. Processing typically includes reclassifying an image to distinguish land surface, surface water, and ground water. However, the thermal infrared images used in this study displayed no consistent difference between land, surface water, and ground water that could represent mine drainage. 


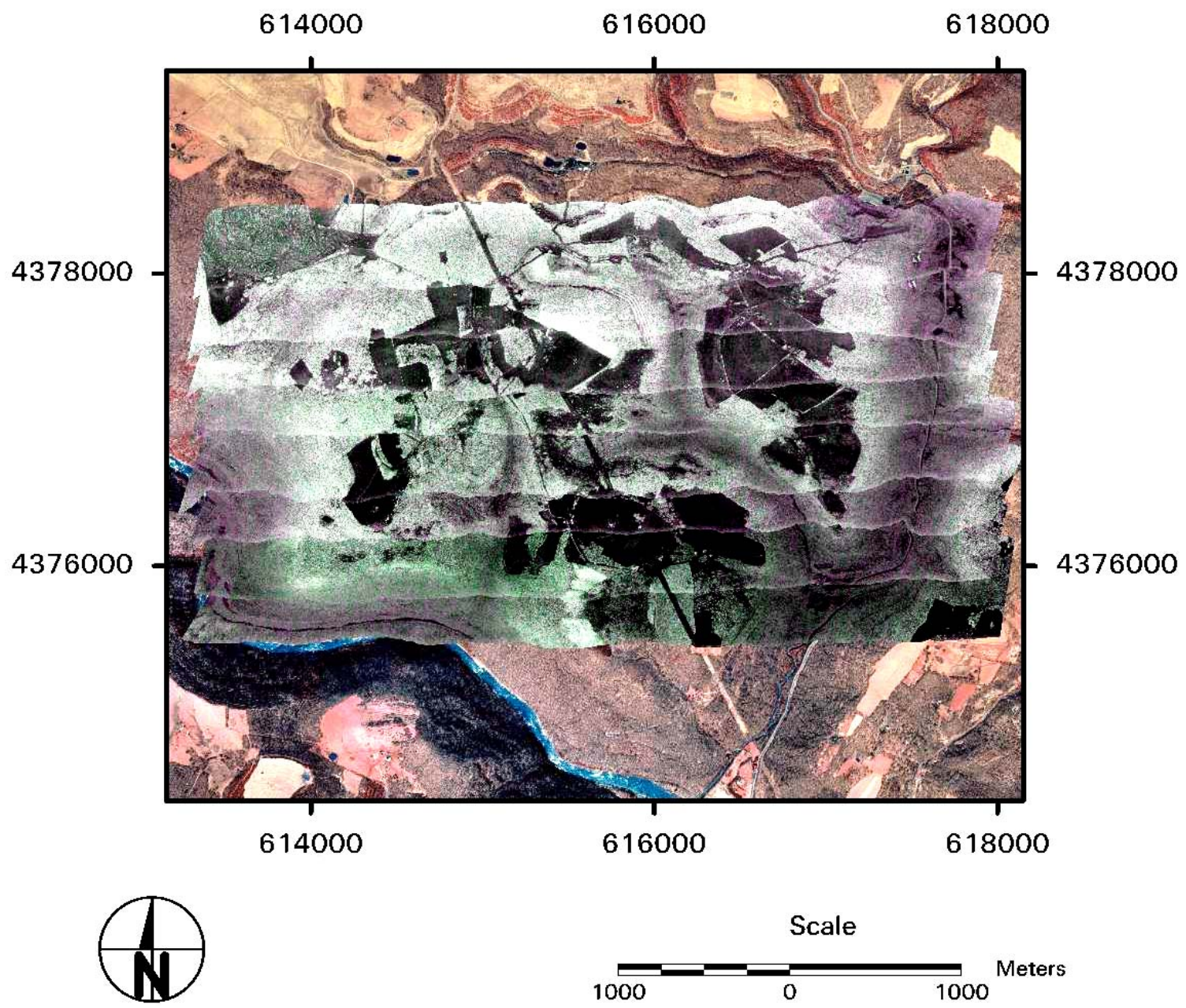

Figure 32: Mosaic of several nighttime TIR flight lines overlain on a false color DOQQ. 
Table 2: Significant layers used in GIS analysis for the T\&T Mine Complex.

\begin{tabular}{|c|c|c|}
\hline Theme & Type & Description \\
\hline TIR_image (lines & raster & Thermal Infrared Image by Line \\
\hline 3-10) & raster & Study Area, USGS Digital Elevation Model \\
\hline Study_Area_DEM & raster & Study Area, USGS Digital Raster Graphic \\
\hline Study_Area_DRG & raster & Study Area, USGS Digital Ortho Quarter Quad \\
\hline Study_Area_DOQ & raster & Study Area, Structure contours of Upper \\
\hline Upper Freeport & Freeport Coal \\
\hline Struct & raster & Apparent Conductivity Map, 102680 Hz \\
\hline Con_102K & raster & Apparent Conductivity Map, 25800 Hz \\
\hline Con_25K & raster & Apparent Conductivity Map, 6254 Hz \\
\hline Con_6200 & raster & Apparent Conductivity Map,1555 Hz \\
\hline Con_1500 & raster & Apparent Conductivity Map, 380 Hz \\
\hline Con_380 & polygon & Extent of Underground Mine \\
\hline Mine Boundary & polygon & Extent of Mine Pools \\
\hline Mine_Pools & polygon & Extent of Surface Mined Areas \\
\hline Surface_Mined & polygon & Boundary of Preston County \\
\hline Preston County & line & Preston Anticline \\
\hline Preston Anticine & line & Kingwood Syncline \\
\hline Kingwood Syncline & line & Streams near mining area \\
\hline Mine_streams & point & Well locations in mine area \\
\hline Well_location & & \\
\hline
\end{tabular}

A pseudocolor scheme was applied to the TIR data to emphasize features of interest (Figure 33). Pseudocolor operations do not alter the integrity of the data. Pseudocolor delivers a normal transition through the color spectrum such that higher DN values are represented by warmer colors, which makes interpretation more intuitive. A predefined color lookup table was applied to the dataset to implement the pseudocoloring of the image. Unfortunately, there was no emphasis of any particular feature of interest as the thermal data is poor in quality. 


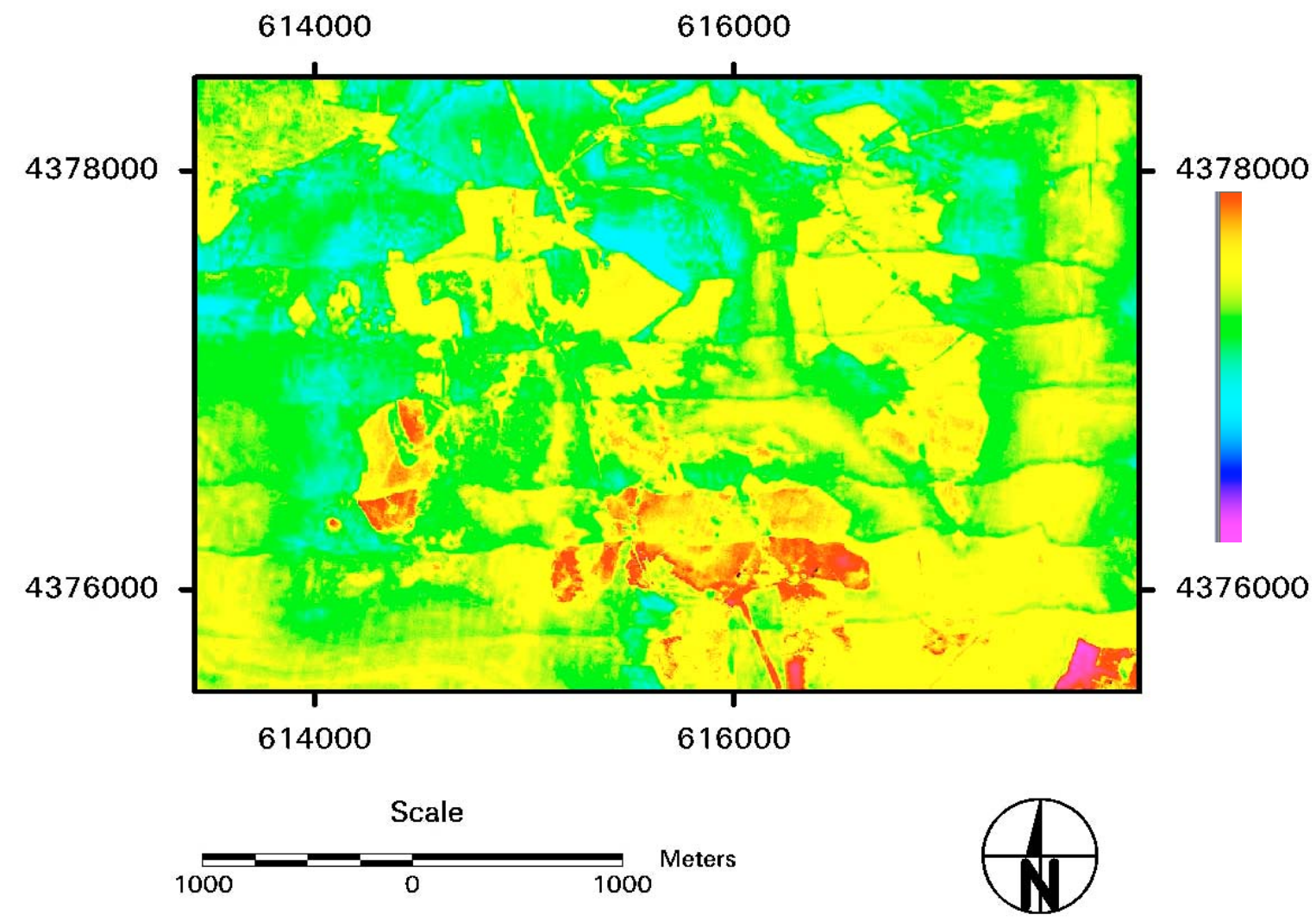

Figure 33: A pseudocolor image of the thermal data. Pseudocoloring was applied in order to highlight possible areas of interest. The applied color scheme is intuitive in nature; red colors are the warmest, blue colors are coolest.

Erdas Imagine has a swipe tool, which allows the user to view two overlain images in a single viewer at the same time. Using this tool, thermal anomalies were located and interpreted. Figure 34 depicts a cluster of thermal anomalies that appear to be livestock. 


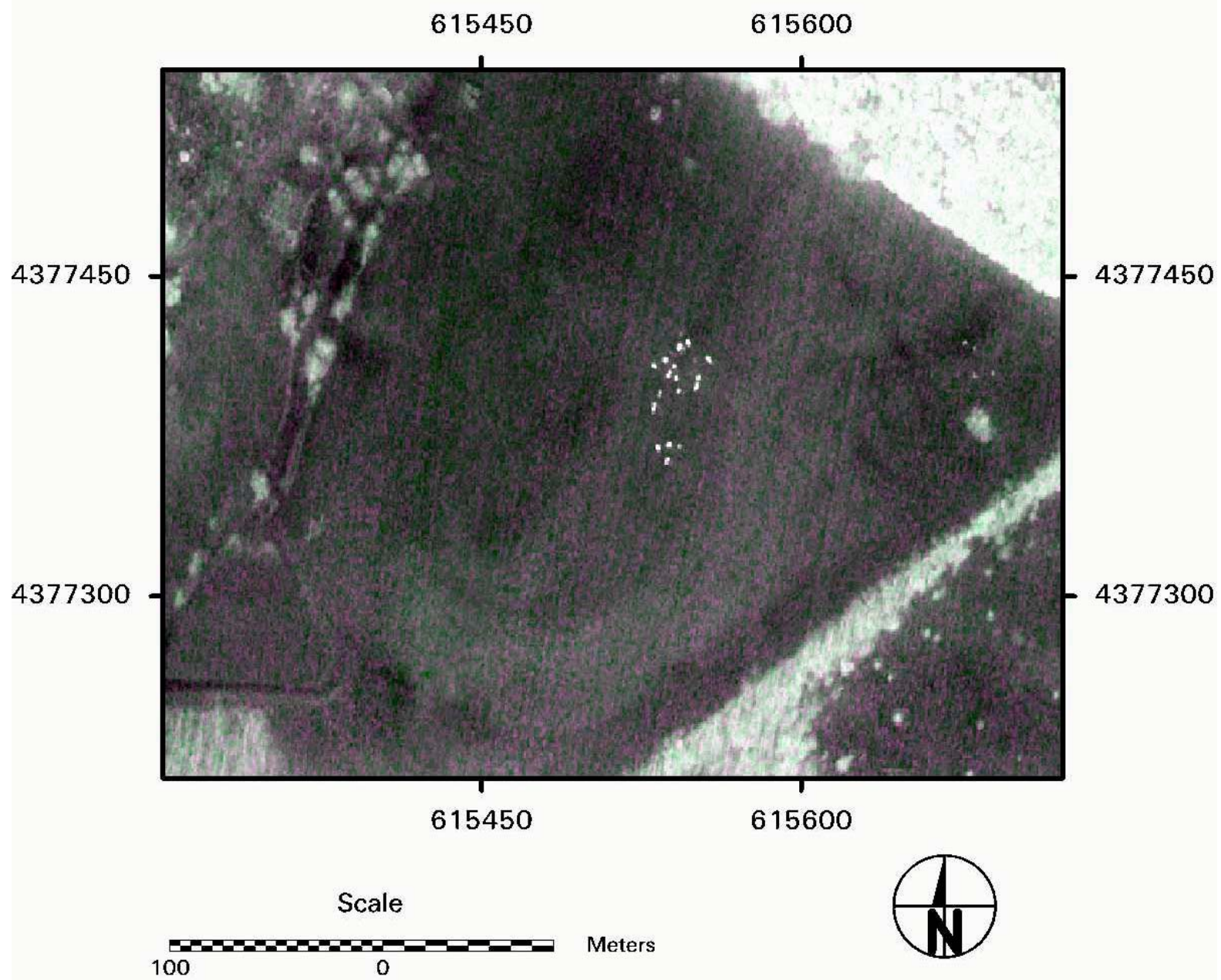

Figure 34: TIR imagery depicting a thermal anomaly that may be interpreted as livestock in the field.

Figure 35 depicts a strip mine area, which has been reclaimed. Note the regular pattern of the conifer trees in the DOQQ. The same pattern is exhibited in the thermal imagery; the rows of the trees are warmer than the immediate surroundings. Coal refuse piles, which are relatively cool when compared to the forested area, can be observed. 
A.

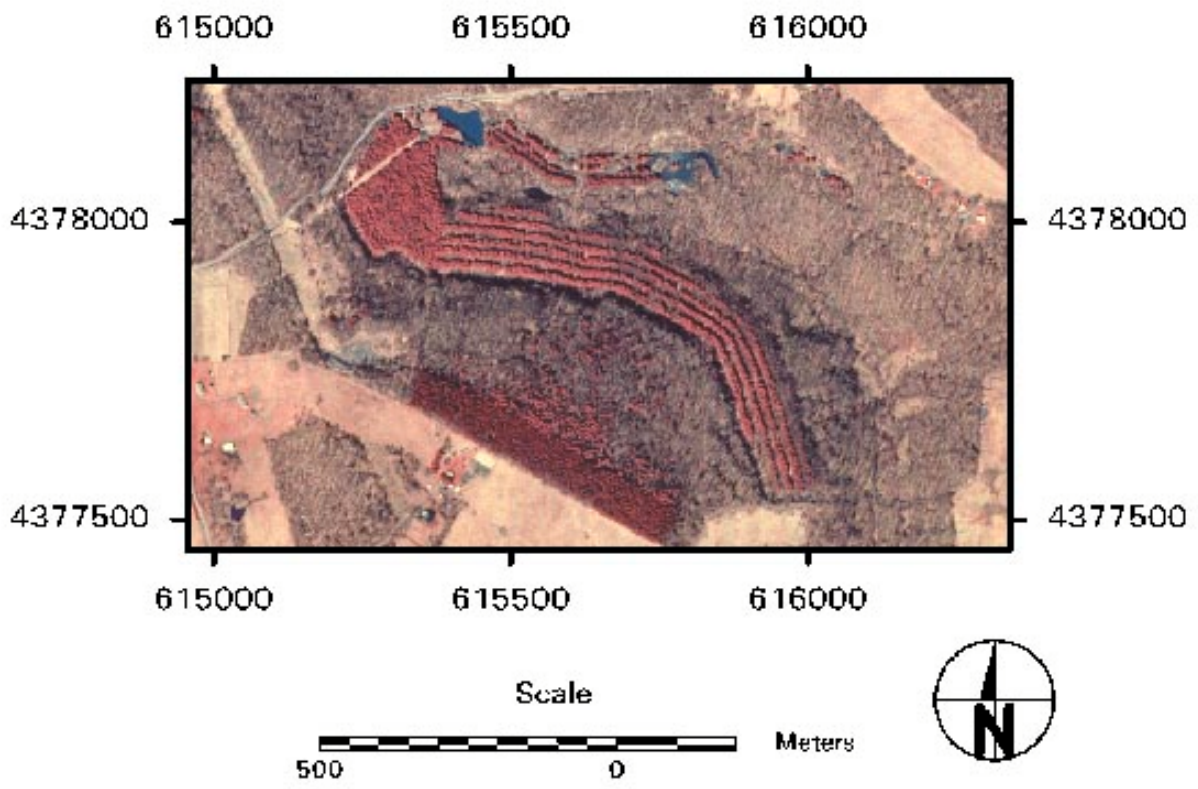

B.

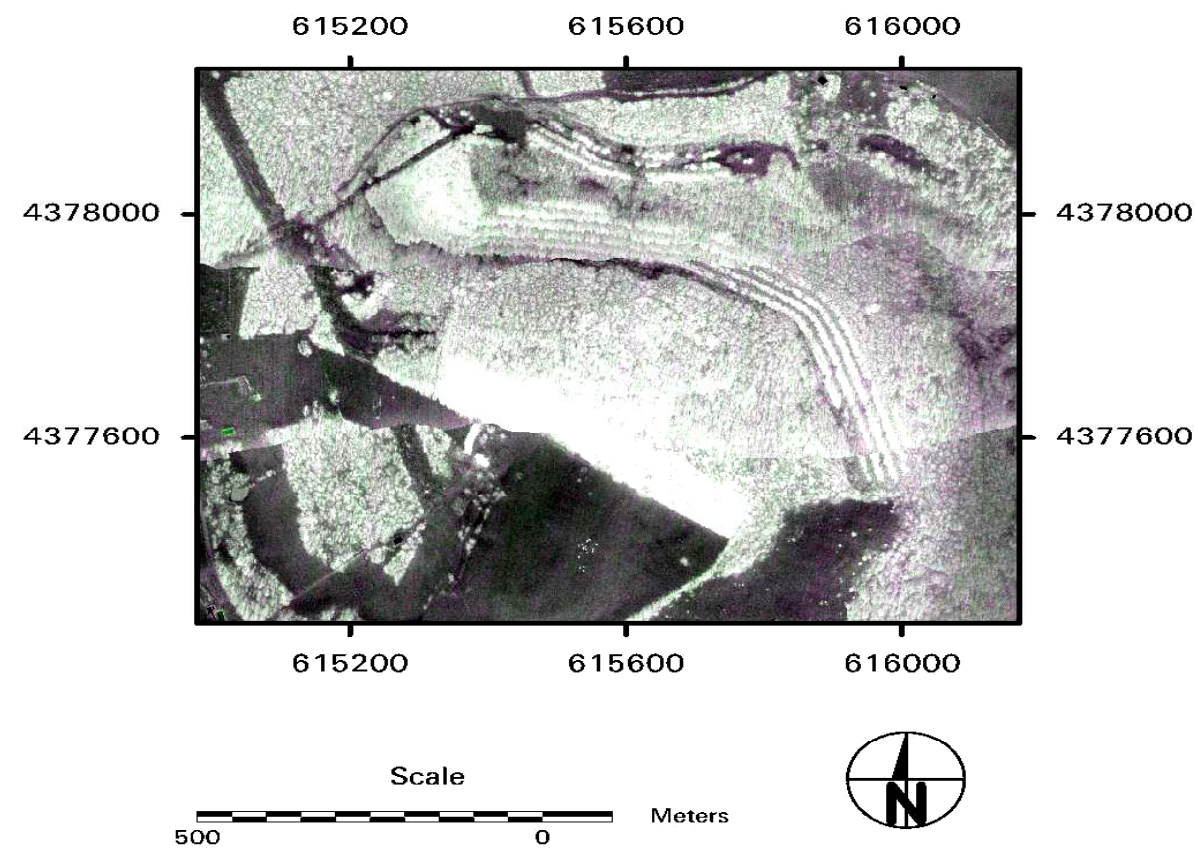

Figure 35 A and B: The TIR imagery compared to a DOQQ. Figure A is a false color DOQQ. Figure B is the TIR imagery of the same area. The reclaimed area is recognizable due to the pattern of the conifer trees. The conifer trees represent a thermal anomaly. 
Although TIR has been found to be successful in locating AMD in previous studies (Sams and Velsoski, 2003), several environmental conditions can limit the effectiveness of using thermal infrared as a method for locating potential mine drainage source areas. First, the path between the source and the airborne sensor must be unobstructed. In forested areas, a leaf-off period is usually selected for data collection. Under normal circumstances in the deciduous temperate forested areas of the same latitude $\left(39^{\circ} \mathrm{N}\right)$ and elevation range $(950-$ 2000 feet) of this study, this period ranges from late October to early April. However, the T\&T Mine Complex survey was performed at the beginning of a leaf-off period (November), and it is possible that some trees had not yet lost all of their leaves. In addition, even areas heavily forested with deciduous trees may be obstructed by tree trunks and branches. Furthermore, evergreen species were a problem for this study, particulary those species planted in the reclamation of the T\&T mine site. In most instances, the coniferous trees obscured thermal emissions from the ground, precluding the possibility of locating features that would otherwise be expected to exhibit strong thermal responses such as a possible mine drainage seep. Additionally, the leaves of coniferous trees exhibit a relatively high radiant temperature due to the thermal storage and emissive properties of the leaves. These warm temperatures associated with conifer trees can be confused with the warm temperatures of the mine drainage. 


\section{Chapter 5 - Conclusions and Significance}

\subsection{Key Findings}

\section{Ground Surveys}

Terrain conductivity and resistivity soundings were acquired at the T\&T mine complex to determine whether they might prove useful for detecting and mapping underground mine pools. The inverse modeling of the terrain conductivity soundings indicates that the mine pool could not be resolved at it's depth of 90 meters. The differences between the observed conductivities and the calculated conductivities could be attributed to local variations in the strata. Another explanation for the differences between the observed and calculated conductivities could be a result of dewatering of upper aquifers via fractures propagating upward from the mine. As the overlying strata subside into the mine void, extension fractures develop. These fractures extend upward into the shallower strata and may penetrate aquifers, allowing for dewatering of the aquifer into lower strata.

Forward conductivity models show that at the depth of 90 meters, the anomaly produced by the mine interval is too small to be detected. Useful information was obtained from the terrain conductivity surveys on the properties of strata in the upper 40 meters.

The resistivity surveys were also unable to resolve resistivity variations associated with the mine workings. Observation of layer resistivities at depths below approximately 10 meters was obscured by the presence of the near-surface highly resistive Grafton Sandstone. This high resistivity layer inhibits electric current flow into deeper formations, making the resistivity survey ineffective. Resistivity models derived from the individual resistivity sounding yielded results similar to those obtained from 2-D inversion of the entire profile. 


\section{Airborne Surveys}

An airborne electromagnetic and thermal infrared imaging survey was conducted over the T\&T Mine Complex to detect potential pollution sources in the Roaring Creek/Muddy Creek watershed area. Another objective of the airborne EM survey was to determine whether these airborne surveys could be used to characterize the near-surface hydrology in coal mining areas. The ability to detect abandoned flooded mine workings in the vicinity of active mines would help avoid accidental breakthrough into the old mine systems.

The airborne conductivity data was deconvolved using EM Flow (Macnae, 2001). CDI's were generated for all the flight lines over the T\&T mining area, but for the purpose of the study, only flight lines that corresponded to well locations were presented. When computing models for the airborne data, the $390 \mathrm{~Hz}$ data had to be excluded due to excessive power line noise. The comparison of airborne CDI's with down-hole induction logs and EM 34 soundings show some agreement. The thin, near-surface conductor could be a result of the deconvolving process. However, the airborne data results do not corroborate ground survey results.

As projected by the forward model of the airborne conductivity data, a conductive mine pool may be detected under optimal conditions at depth of approximately 40 meters. Therefore, there was little chance that the survey at the T\&T Mine Complex could detect conductive mine pools at 90-m depth. Furthermore, the execution of this survey was suboptimal. Should the airborne survey be conducted such that the bird maintained the optimal height above ground $(30 \mathrm{~m})$ and the study area had minimal powerline and cultural 
interference, the HEM survey results may have detected mine pools up to a depth of approximately 40 meters.

The CDI's do not indicate a conductive anomaly at the depth and location of the known conductive mine pool. There is a conductive layer near the surface that roughly follows topography. This conductive layer is thought to correspond with the highly conductive layer observed in the well logs, and could be the local water table. The conductive anomalous regions observed at depth are much deeper than the mine pools and are thought to be a result of noise. Distinctive anomalous regions at depth are associated with power line location and areas in which the maximum sensor height was greatly exceeded.

The average depth to the mine pool is about $90 \mathrm{~m}$ along the flight lines, which is much greater than the depth limit for detection under optimal conditions. However, correctable problems with this survey may have been responsible for the non-detection of the mine pool. The $390 \mathrm{~Hz}$ data could not be used in forward modeling calculations due to noisy data because the external noise precluded the depth advantage. Some noise can be attributed to the high-voltage power line that extends across the site and is unavoidable. Rugged topography, an inexperienced helicopter pilot, excessive sensor height, swinging of the bird, and interference from power lines resulted in sub-optimal survey execution and noisy data. The mine pools were not detected.

Thermal imagery has been successfully used to detect groundwater discharging at the surface in mining areas in the Appalachian region in order to further characterize watersheds. However, the thermal infrared imagery collected at the T\&T Mine Complex was not useful in determining potential acid mine drainage discharge points. The survey 
was undertaken during the leaf-off period, however, the numerous coniferous trees obscured the ground thermal patterns. Anomalies present in the TIR images of the T and T Mine Complex are not associated with groundwater discharge, but rather cultural features and forested areas, including both natural forestlands and reclaimed areas.

\subsection{Significance of Findings}

This study provided an opportunity to evaluate the use of airborne and ground geophysical and remote sensing techniques to detect mine pools and possible acid mine drainage source areas in an area with both underground and surface mine sites. This study served as a benchmark for the potential of geophysical methods for mine site evaluation. Though the surveys did not successfully delineate the mined areas, they should serve as a starting point for further investigations for the use of geophysical methods in an environmental application. Previous studies have shown that airborne and ground-based geophysics and remote sensing can be successfully employed to delineate vertical and horizontal extents of mined areas. This study shows the potential and limitations of geophysical survey methods conducted to resolve near surface conductivity and resistivity variations over underground mine complexes.

\subsection{Suggestions for Future Work}

Future geophysical efforts at such sites should utilize modeling efforts before geophysical surveys are planned in order to determine if areas of interest can be detected using this methodology.

For airborne geophysical surveys, planners should if possible avoid areas with significant sources of cultural interferences such as power lines, towns, and pipelines. A pilot who is comfortable and experienced flying a sling load in rugged terrain should be 
employed for such survey endeavors. When considering a nighttime thermal infrared survey, planners should ensure that the flight takes place in a leaf-off period and in an area that is not dominated with coniferous trees.

Ground surveys should be strategically located to minimize depth to the target intervals. Mine pool depth at the T\&T Mine Complex exceeded 80 meters at ground survey locations, a depth too great to be accurately sensed using the geophysical methods employed in this study. 


\section{References}

Ackman, T.E., G.A. Veloski, R.A. Dotson, Jr., R.W. Hammack. An Evaluation of Remote Sensing Technologies for Watershed Assessment. U.S. Department of Energy, National Energy Technology Laboratory, Pittsburgh, PA.

Ackman, T.E., and K.K. Cohen, 1994. Geophysical Methods: Remote Techniques Applied to Mining-related Environmental and Engineering Problems. U.S. Department of Energy, National Energy Technology Laboratory, Pittsburgh, PA.

Burger, Robert H. 1992. Exploration Geophysics of the Shallow Subsurface. pp. 310,405 .

Brewster, S. B. 1999. Geometric Correction System Capabilities, Processing, and Applications, Fourth International Airborne Remote Sensing Conference and Exhibition $/ 21^{\text {st }}$ Canadian Symposium

Fugro-Geoterrex Dighem, Inc., 2000. Report for US Dept. of Energy, Federal

Energy and Technology Center over the Cheat River Watershed, \#996004.

Hammack, R. W., and Mabie, J.S., 2002. The Use of Airborne EM Conductivity to Locate Contaminant Flow Paths at the Sulphur Bank Mercury Mine Superfund Site. Proceedings for the Symposium on the Application of Geophysics to Environmental and Engineering Problems, Feb 10-14.

Keller, George V., 1997. Principles of Time-Domain Electromagnetic (TDEM) Sounding. The Leading Edge, April: 355-357.

Keller, George V. and Frischknecht, Frank C., 1966. Electrical Methods in Geophysical Prospecting. Oxford, New York, Pergamon Press.

Keys, S.W., 1988. Borehole Geophysics Applied to Groundwater Investigations. Techniques of Water Resource Investigations of U.S. Geological Survey, Book 2, Chapter E2: 1-105.

King, A.R. and Hynes, T., 1994. Application of Geophysical Methods for Monitoring Acid Mine Drainage. Proceedings for International Land Reclamation and Mine Drainage Conference, April 24-29: 317-326. 
Interpex Limited, 2001. www.interpex.com/em.htm

Ladwig, Kenneth, 1983. Electromagnetic Induction Methods for Monitoring Acid Mine Drainage. Ground Water Monitoring Review. Winter: 46-51.

Lillesand, T. M. and Kiefer, R. W. (1994), Remote Sensing and Image Interpretation, New York: John Wiley \& Sons, Inc. $3^{\text {rd }}$ Ed.

McNeill, J.D. 1980-a. Electrical Conductivity of Soils and Rocks. Geonics Limited, TN-5.

McNeill, J.D. 1980-b. Electromagnetic Terrain Conductivity Measurements at Low Induction Numbers. Geonics Limited, TN-6.

McNeill, J.D., 1980-c. Application of Transient Electromagnetic Techniques. Geonics Limited, TN-7.

McNeill, J.D. and V.F. Labson. Geologic Mapping using VLF Radio Fields pp.521-640.

McNeill, J.D., 1990. Use of Electromagnetic Methods for Groundwater Exploration in Geotechnical and Environmental Geophysics. Investigations in Geophysics, S.H. Ward (ed.), no. 5: 191-218.

Mabie, J.S., Hammack, R.W., and Veloski, G.A., 2002. Airborne and Ground-Based Investigations of the North Fork of Yellow Creek, Jefferson County, Ohio. Proceedings for the Acid Mine Drainage Task Force, April.

Macnae, James, 2001. EM Flow Experienced User Manual, Version 5.10 http://www.encom.com.au/pages/swef.htm

Merkel, R.H., 1972. The Use of Resistivity Techniques to Delineat Acid Mine Drainage in Ground Water. Ground Water, 10 (5): 38-42.

Tasci, M.T. and Jordan, J.M. Case Histories Using the Time Domain Electromagnetic Sounding Method in Oil and Gas Exploration. Submitted to Geophysics, Journal of Society of Exploration Geophysicists. www.geotech.org/survey/stratas/casehist/casehist.htm

Torgerson, C., Faux, R.N., McIntosh, B.A., Poage, N.J., Norton, D.J., 2001. Airborne Thermal Remote Sensing for Water Temperature Assesement in Rivers and Streams. Remote Sensing of the Environment, 76:386-398.

Sams, J. and Veloski, G, 2003, USDOE Report. Anaylsis of TIR data acquired for Kettle 
Creek Watershed. Unpublished.

Stoller, R.L., and Roux, P., 1975. Earth Resistivity Surveys - A Method for Defining Ground Water Contamination. Ground Water, 13(2): 145-150.

Stoyer, C.H., 1998. Vertical Resolution and Equivalence in EM Soundings. Interpex Limited, SAGEEP Workshop.

Yazicigil, H. and Sendlein, V.A., 1982. Surface Geophysical Techniques in Groundwater Monitoring Part II. Ground Water Monitoring Review, Winter. 